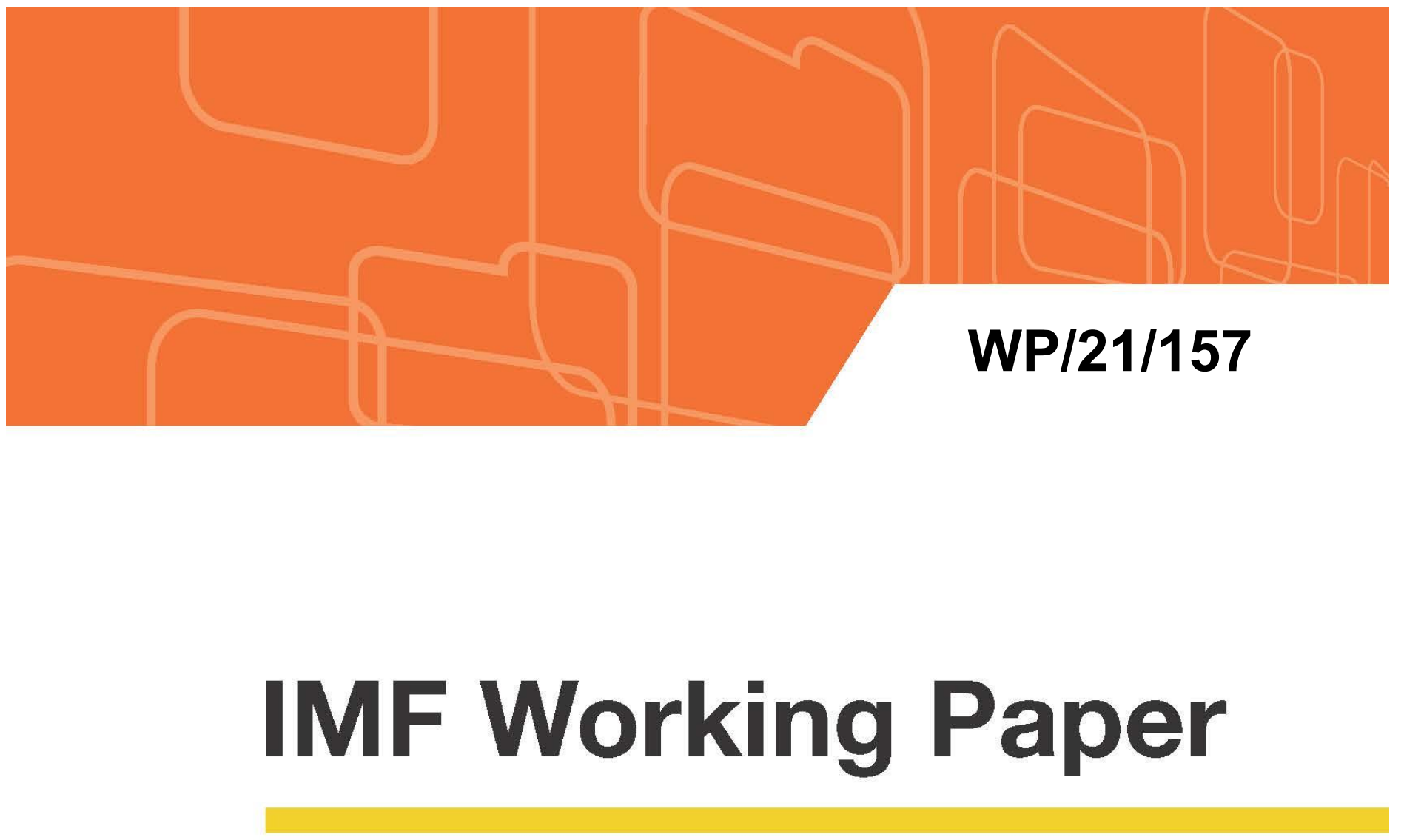

\title{
COVID-19 Containment Measures and Expected Stock Volatility: High-Frequency Evidence from Selected Advanced Economies
}

by Viral V. Acharya, Yang Liu, and Yunhui Zhao

IMF Working Papers describe research in progress by the author(s) and are published to elicit comments and to encourage debate. The views expressed in IMF Working Papers are those of the author(s) and do not necessarily represent the views of the IMF, its Executive Board, or IMF management. 
IMF Working Paper

Strategy, Policy, and Review Department

\title{
COVID-19 Containment Measures and Expected Stock Volatility:
}

\section{High-Frequency Evidence from Selected Advanced Economies}

\author{
Prepared by Viral V. Acharya (NYU), Yang Liu, Yunhui Zhao (both IMF) ${ }^{1}$ \\ Authorized for distribution by Daria Zakharova
}

June 2021

\section{IMF Working Papers describe research in progress by the author(s) and are published to elicit comments and to encourage debate. The views expressed in IMF Working Papers are those of the author(s) and do not necessarily represent the views of the IMF, its Executive Board, or IMF management.}

\begin{abstract}
We study the effect of COVID-19 containment measures on expected stock price volatility in some advanced economies, using event studies with hand-collected minute-level data and panel regressions with daily data. We find that six-month-ahead volatility indices dropped following announcements of initial or re-imposed lockdowns, and that they did not drop significantly following the easing of lockdowns. Such patterns are not as strong for three-month-ahead expected volatility and generally absent for one-month-ahead expected volatility. These results provide suggestive evidence for the existence of an intertemporal trade-off: although stringent containment measures cause short-term economic disruptions, they may reduce medium-term uncertainty (reflected in expected stock volatility) by boosting markets' confidence that the outbreak would be under control more quickly.
\end{abstract}

JEL Classification Numbers: C50, G10, G12, H00, H12

Keywords: COVID Containment, Trade-off, Volatility, Uncertainty, Event studies Authors’ E-Mail Addresses: vacharya@stern.nyu.edu; yliu10@imf.org; yzhao@imf.org

\footnotetext{
${ }^{1}$ We are gratefulfor the helpful discussions with Alberto Behar(IMF, unless otherwise stated), Jorge Chan Lau, Martin Cihak, Rupa Dutta gupta, Alan Xiaochen Feng, Gita Gopinath, Burcu Hacibedel, Sandile Hlatshwayo, Anna Ilyina, Timothy Johnson (UIUC), Andra s Komaromi, Romain Lafarguette, Wojciech Ma liszewski, Jonathan Ostry, Chris Redl, Agustin Roitman, Eddy Tam (Oxford), Yannick Timmer, Wenta o Xiong (Goldman Sachs), Daria Zakharova, Ta o Zhang, and participants at the IMF interdepartmental surveillance meeting in October 2020 and at the SPARK series. We also thank William Kunxiang Diao for his excellent support on updating the vola tility data, and Tia na Wang for her excellent resea rch a ssista nce.
} 


\section{CONTENT}

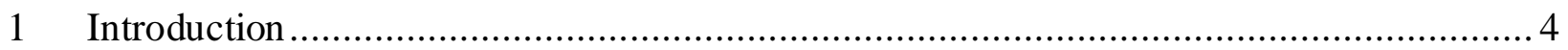

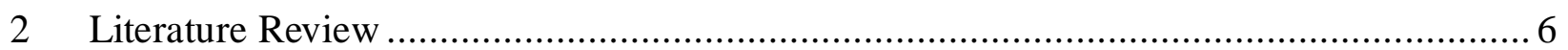

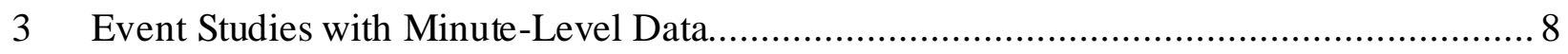

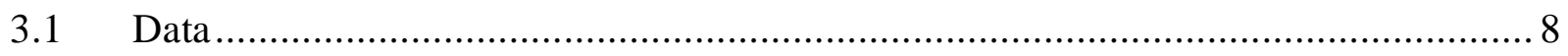

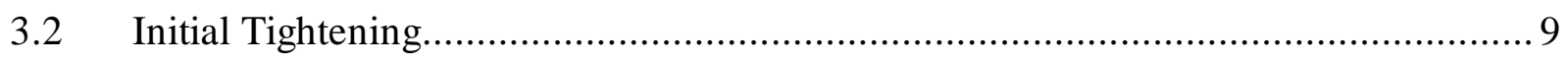

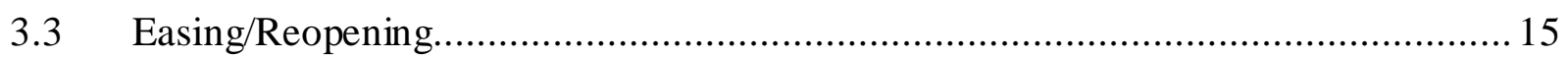

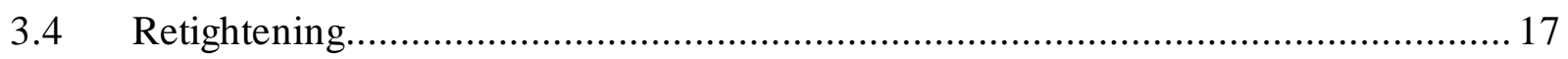

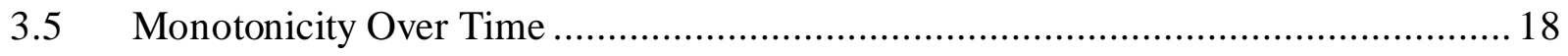

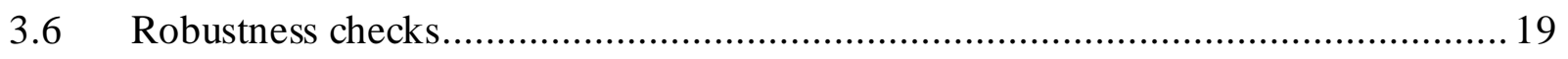

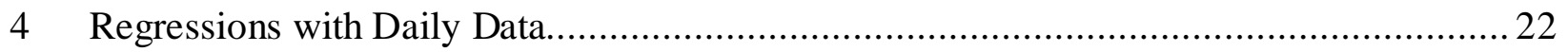

$4.1 \quad$ Data

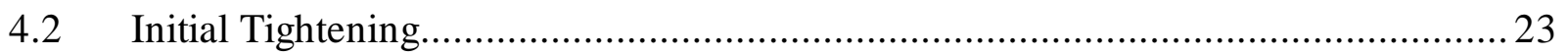

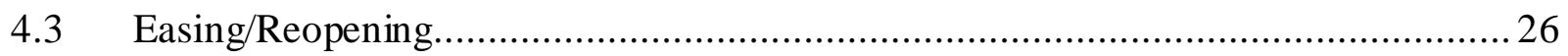

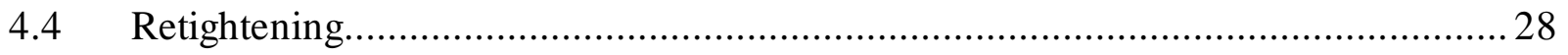

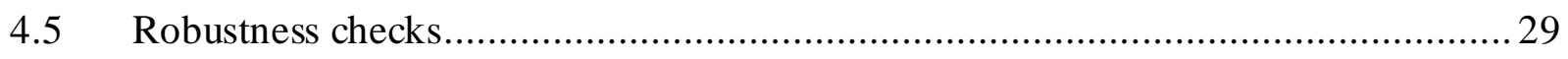

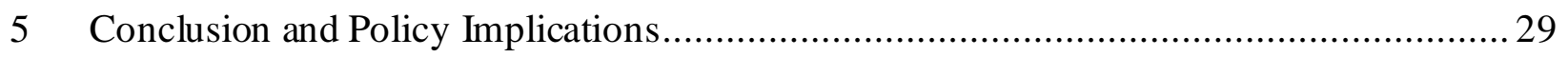

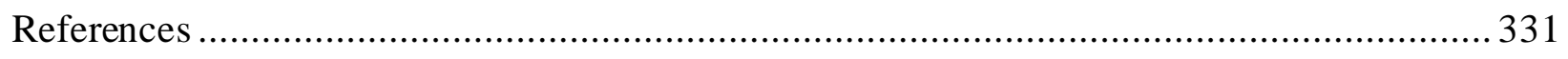

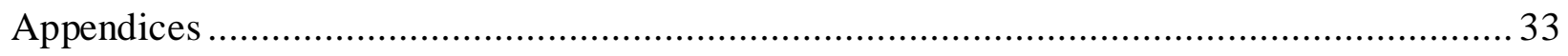

\section{Figures}

Figure 1. Six-Month Volatility Indices (Initial Tightening)................................................... 13

Figure 2. Prediction Errors for Six-Month Volatility Indices (Initial Tightening)...................... 14

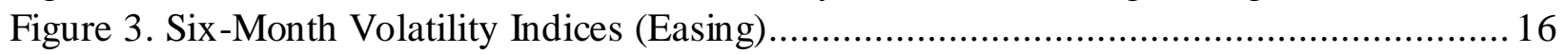

Figure 4. Six-Month Volatility Indices (Retightening)........................................................ 17

Figure 5. Volatility Responses Across Maturities: Germany's Initial Tightening (Local Market) 
Figure 6. Volatility Responses Across Maturities: France's Initial Tightening.......................2 21

Figure 7. Volatility Responses Across Maturities: Germany’s Retightening (Local Market) ..... 22

Figure 8. Interaction Between Stringent Containment Measures and COVID Case Growth ...... 25

\section{Tables}

Table 1. Summary Statistics of Event Study Data ......................................................... 9

Table 2. Macroeconomic Relevance of Volatility Indices.............................................. 15

Table 3. Initial Tightening Stage Panel Regressions in the Full Model............................... 25

Table 4. Panel Regressions in the Full Model: Easing and Retightening Stages .................... 27

\section{Appendix Figures}

Appendix Figure 1. Prediction Errors for Six-Month Volatility (Easing)............................. 34

Appendix Figure 2. Prediction Errors for Six-Month Volatility (Retightening)....................... 34

Appendix Figure 3. Volatility Responses Across Maturities: Italy's Initial Tightening ............ 35

Appendix Figure 4. ARIMA Model: Six-Month Volatility Indices (Initial Tightening)............ 36

Appendix Figure 5. ARIMA Model: Six-Month Volatility Indices (Easing).......................... 37

Appendix Figure 6. ARIMA Model: Six-Month Volatility Indices (Retightening).................. 37

Appendix Figure 7. EGARCH Model: Six-Month Volatility Indices (Initial Tightening)......... 38

Appendix Figure 8. EGARCH Model: Six-Month Volatility Indices (Easing)........................ 39

Appendix Figure 9. EGARCH Model: Six-Month Volatility Indices (Retightening)................ 39

\section{Appendix Tables}

Appendix Table 1. Summary Statistics of Panel Regression Data ..................................... 40

Appendix Table 2. Initial Tightening Stage Panel Regressions in the Benchmark Model......... 41

Appendix Table 3. Initial Tightening Stage Panel Regressions in the Stock Price Model ......... 41

Appendix Table 4. Seemingly Unrelated Regression Results (Full Sample, All Stages) ............ 42 


\section{$1 \quad$ Introduction}

This paper aims at illustrating an economic benefit of COVID-19 containment measures reflected in lower expected stock price volatility. On such measures, many discussions focus disproportionally on their humanitarian benefit and characterize them as saving lives at the cost of sacrificing the economy or livelihoods. This perception has been the main reason for governments' reluctance to impose lockdowns and their rush to reopen the economies. However, despite the short-term economic disruptions, containment measures may also have a significant economic benefit, particularly over the medium term - they could help contain the outbreak, buy time for vaccination rollout and herd immunity, reduce uncertainty, and mitigate health/financial constraints. ${ }^{2}$ These arguments are consistent with some market participants' views that investors' optimism can sustain only if they are confident that the outbreak is under control. ${ }^{3}$ They are also in line with the views of some policymakers. ${ }^{4}$

However, there are at least two challenges for quantifying the economic benefits of containment measures. First, it is hard to distinguish between short-term costs and medium-term benefits of containment measures, given that the observed macroeconomic data reflect both the costs and benefits. Second, most macroeconomic data are available at relatively low frequency (monthly or quarterly), making the identification of the effects of containment measures difficult. To overcome thesechallenges, we proxy the "medium-termuncertainty" with the six-month-ahead stock price volatility indices implied by options prices; we then use the reduction in these indices to measure the economic benefit of containment measures. We also conduct the analysis separately for the initial tightening stage, the easing/reopening stage, and the retightening stage to account for the different impacts of containment measures at different stages. Specifically, two complementary approaches are employed in each stage.

First, using minute-level data, we conduct event studies for an extreme containment measure-lockdown. To do so, we take a deep dive into multiple information sources (such as English newspapers, local language newspapers, tweets, and government websites) and manually identify the minute when a COVID-related lockdown or reopening was announced. We then conduct event studies by comparing the post-announcement actual volatility indices with their counterfactuals. Due to limitations of the volatility data, only the US, Italy, Germany, and the eurozone are covered. To focus on systemic events only, we study the most significant

\footnotetext{
2 Although containment measures may be less effective in countries with large informal sectors, the aforementioned benefit still exists in all countries and needs to be considered to properly assess the trade-off associated with containment measures.

3 "US stocks in sharp late rally on hopes virus is slowing," Financial Times, April 7, 2020.

${ }^{4}$ One example is IMF Managing Director's statement that "the faster the virus stops, the quicker and stronger the recovery will be."
} 
lockdown/reopening announcements by the aforementioned countries/regions. ${ }^{5}$ Despite the small number of events, this approach has the advantage of mitigating the omitted variable bias commonly encountered in regression-based approaches. Various models are used to construct the counterfactuals, such as GARCH and EGARCH, and additional variables are controlled to account for other forces (e.g., fiscal stimulus) that may be at play at the time of the announcements.

Second, using daily data, we conduct panel regressions for broader containment measures (such as a moderate restriction on gathering) instead of a full-fledged lockdown. This approach regresses the daily volatility indices on a comprehensive stringency index of containment measures constructed by Oxford University for largely the same set of countries/regions as in the first approach. There are not many variations in the stringency index data due to the relatively infrequent policy measure changes, and there are many other forces that affect volatility. To address these concerns, we include the relevant stock price indices in the regressions in an attempt to control for the impacts of other driving forces in a parsimonious way. Since COVID-19 is a global shock, seemingly unrelated regressions are also conducted to account for the correlations among different countries and different volatility products.

Both approaches produce very similar results. First, during the initial tightening stage, stringent containment measures significantly reduce expected stock volatility, which directly supports our hypothesis stated above. Second, the easing of stringent containment measures is not associated with a significant reduction in expected volatility, contradicting the conventional wisdom (i.e., the easing of containment means less disruptions to the economy and lower uncertainty) and thus indirectly supporting our hypothesis. Third, during the retightening stage, more stringent containment policies are associated with lower expected volatility, although its statistical significance is lower than the initial tightening stage. ${ }^{6}$

In particular, the above results are the strongest for six-month-ahead expected volatility, not as strong for three-month-ahead expected volatility, and generally absent for one-month-ahead expected volatility (the left three panels in Figure 5). Although we do not study the volatility beyond the six-month horizon due to data limitations, the increasing significance of results over time seems informative. Taken together, the results provide suggestive evidence for the existence of an intertemporal trade-off: although stringent containment measures cause short-term economic

\footnotetext{
${ }^{5}$ For the initial tightening stage, the events include (1) Trump's state-of-emergency declaration on March 13 that enabled sta tes to impose lockdowns; (2) California's stay-at-home order on March 19, the very first statewide lockdown in the US; (3) Ita ly's nationwide lockdown on March 9; (4) Germany's na tionwide lockdown on March 16, which was widely regarded as a historic move by the press (for this event, we have data on both the domestic and eurozone-wide volatility); (5) France's nationwide lockdown on March 16.

${ }^{6}$ This could reflect market participants' perception that the conta inment measures at the retightening stage are less stringent than the initial stage, which may be inadequate to contain the second wa ves and thus volatility did not drop as much.
} 
disruptions, they may reduce medium-term uncertainty (reflected in expected stock volatility) by boosting markets' confidence that the outbreak would be under control more quickly.

The remainder of the paper is organized as follows. Section 2 reviews the related literature. Section 3 discusses the minute-level event studies, including the dataset, the methodology, and the results for the three stages. Section 4 discusses daily-level regressions. Section 5 concludes and discusses some policy implications.

\section{$2 \quad$ Literature Review}

Our paper relates to a growing literature on the effects of COVID-19 and containment measures. First, it relates to the literature on the COVID-era financial market responses. Beirne et al. (2020) find that emerging economies in Asia and Europe experienced the sharpest declines in stocks, bonds, and exchange rates due to COVID-19. Using data since January 1900, Baker et al. (2020) find that no previous infectious disease outbreak increased the US stock market volatility as forcefully as the COVID. Focusing on industry-specific realized volatility, Baek, Mohanty, and Glambosky (2020) find that changes in volatility are more sensitive to COVID news than to economic indicators. Using daily data and ARMA models, Cheng (2020) studies the futures of VIX (rather than the VIX itself, as we do) and finds that the VIX futures market underreacted to the growing risks of the pandemic during the early stages. ${ }^{7}$ Our paper complements these studies by focusing on the effect of containment measures and examining the minute-level, forwardlooking volatility data right after a lockdown announcement, which is more likely to separate the effect of containment from that of other driving forces, such as the COVID outbreak itself.

Second, our paper relates to a large literature that points to a high economic cost of containment measures. For example, Deb et al. (2020a) find that containment measures are associated with a $15 \%$ decline in industrial production over a 30-day period. Kok (2020) finds that during the second quarter of 2020, "containment and closure policies" deducted about $8.6 \%$ (yearon-year) of GDP growth for advanced economies and 5.1\% for Emerging Market and Developing Economies. However, some other studies suggest a mixed picture. Caselli et al. (2020) find that voluntary social distancing also contributed to short-term economic contractions. Goolsbee and Syverson (2020) find that legal shutdown orders account for only 7 of the 60 percentage-point decline of consumer visits to businesses, and that individual choices due to infection fears were a far more important factor. Chen et al. (2020) find that deterioration of economic conditions preceded the introduction of non-pharmaceutical interventions (NPIs). Aum, Lee, and Shin (2020b) find that at most half of the job losses in the US and the UK can be attributed to lockdowns. Amon, Ricco, and Smetters (2020) find that NPIs explain only about $15 \%$ of the decline in employment.

\footnotetext{
${ }^{7}$ Jackwerth (2020) uses the derived distribution from option prices to discuss the market prediction of the future SP500 index in the COVID era (rather than the prediction of VIX as we do). A few other papers on stock market volatility include Zhang, Hu, and Ji (2020), Zaremba et al. (2020), and Haroon and Rizvi (2020).
} 
Relatedly, in terms of the optimal lockdown policy, Alvarez, Argente, and Lippi (2020) models a planner who balances the fatality induced by the pandemic with the output costs of the lockdown policy. This is the standard life-livelihood trade-off, a framework adopted by a large number of studies. For example, under assumptions about the value of lives saved in the UK, Miles, Stedman, and Heald (2020) conclude that "the costs of continuing severe restrictions are so great relative to likely benefits in lives saved that a rapid easing in restrictions is now warranted." 8

Third, our paper relates to the literature on the benefits of containment measures. Deb et al. (2020b) find that such measures have been very effective in flattening the pandemic. Correia, Luck, and Verner (2020) analyze monthly data across US cities during the 1918 Flu Pandemic, and find that NPIs are associated with better economic outcomes in the medium term. ${ }^{9}$ Using a macroeconomic model calibrated to Korea and UK COVID dynamics, Aum, Lee, and Shin (2020a) find that a longer lockdown eventually mitigates the GDP loss, with a focus on the work-fromhome channel, i.e., the lockdown lowers infections and induces people to switch from working from home (assumed to be less productive) to working on site.

Perhaps the two empirical papers most related to ours are by Sheridan et al. (2020) and Ashraf (2020). Using daily consumer spending data from a large bank in Scandinavia and exploiting an exogenous difference in COVID responses between Denmark and Sweden, Sheridan et al. (2020) find that social distancing laws may provide an econo mic benefit by reducing the economic activity of the low-risk population, lowering the overall prevalence of the virus in the society, and thus attenuating the COVID-induced drop in spending for high-risk individuals. Using daily stock market return data during January 22-April 17, 2020 from 77 countries, Ashraf (2020) finds that announcements of government social distancing measures have both a direct negative effect on stock market returns and an indirect positive effect through the reduction in COVID cas es.

Our paper differs from these two in several dimensions. In terms of methodologies, in addition to using daily data, we employ minute-level event studies and account for other policies

\footnotetext{
${ }^{8}$ Below are some otherexamples using this framework. Eichenbaum, Rebelo, and Trabandt(2020) find that the competitive equilibrium is not socially optimal due to externality, and that the best simple containment policy increases the severity of the recession but saves roughly half a million lives in the U.S. Jones, Philippon, and Venkateswaran (2020) find that private mitigation reduces the cumulative death rate by more than the planner does, a lbeit at the cost of a sharper drop in consumption. Hall, Jones, and Klenow (2020) estimate that the planner is willing to give up $41 \%$ of consumption for a full year to avoid the elevated mortality associated with the pandemic. Gourinchas (2020) concludes that "the measures that help solve the health crisis can make the economic crisis worse - at least in the short run."

${ }^{9}$ Relatedly, Fotiou and Lagerborg (2021) find that countries with previous SARS experience were able to both conta in COVID-19 and mitiga te lockdown-a ssocia ted economic costs due to a "smart" containment stra tegy . Barro, Ursua, and Weng (2020) also quantify the medium-to-long-term effects by analyzing a nnual data for 48 countries. They find that the 1918 Flu Pandemic lowered realGDP by $6-8 \%$ in the typicalcountry, which is suggested to be the upper bound of the effects of COVID-19.
} 
(e.g., fiscal stimulus), providing a potentially cleaner identification. In terms of the scope, in addition to the initial lockdown stage, we also analyze the easing stage and the retightening stage.

\section{$3 \quad$ Event Studies with Minute-Level Data}

\subsection{Data}

Our data on the minute-level event times are hand-collected. Specifically, we take a deep dive into multiple information sources, such as English newspapers, local language newspapers, tweets of reporters, videos of the actual announcements, and government websites. We then manually identify the minute when a COVID-related lockdown or reopening was announced. In case the precise minute cannot be identified, we make our best estimate based on all available information. For example, the minute of France's reopening announcement is estimated using a three-step procedure (Appendix 1). For the announcements made outside of the trading hours, we treat the next opening minute as the event time; and to account for potentially higher fluctuations of the volatility indices right after the opening of markets, our counterfactual models have explicitly introduced a dummy variable for the first 30 minutes after the opening. The same treatment is applied to the last 30 minutes of the trading day.

As for the response variable of the event studies - medium-term expected volatility, we proxy it by the six-month-ahead options-based volatility indices. These indices are based on the core stock price index of the country/region (e.g., S\&P 500 for the US), and they estimate the expected volatility by aggregating the weighted prices of the stock price index puts and calls over a wide range of strike prices (CBOE White Paper, 2019). In the case of the US, these are the sixmonth equivalents of the VIX Index, which measures the one-month-ahead expected volatility and is often referred to as the "fear gauge." We choose three and six months because these horizons represent the "medium-term" to some extent and because data for longer horizons are not available in all countries we study (only the US has the one-year-ahead volatility index).

The minute-level data on expected volatility are from Bloomberg. Specifically, for the US events, we use the CBOE S\&P 500 three-month and six-month expected volatility indices. For all events in Italy, Germany, and France, we use the Euro STOXX 50 expected volatility index, which is widely viewed as Europe's equivalent of the VIX in the US (See Smith, 2013, among others). For events in Germany, in addition to the eurozone-wide volatility index, we also use Germany's country-specific expected volatility index based on the DAX stock price index. However, no intraday expected volatility data are available for Italy, and no data beyond one month are available for France, so events in these two countries are only studied based on the eurozone-wide volatility index. The minute-level data on the underlying stock price indices from Bloomberg are also used in the construction of the counterfactual models.

Table 1 provides the summary statistics of the volatility and stock price index data. For all countries/regions, the data used in our event studies cover the business days from January 2, 2020 
to October 29, 2020, around 210 days in total (the specific number of days varies slightly, depending on the particular country/region and on the maturity, i.e., six-month or three-month). To gauge the magnitude of the post-event change in volatility relative to the "usual" daily change, we also provide the mean of the daily changes across all days, where the daily change is defined as the highest volatility minus the lowest volatility observed during the day. Note that Table 1 does not distinguish between stages (initial tightening, easing, or retightening) because all stages use the same data to train the volatility prediction models.

Table 1. Summary Statistics of Event Study Data

\begin{tabular}{|l|c|c|c|c|c|c|}
\hline & $\begin{array}{c}\text { Number } \\
\text { of obs }\end{array}$ & Mean & Sd & $\begin{array}{c}\text { Number } \\
\text { of days }\end{array}$ & $\begin{array}{c}\text { Daily } \\
\text { change mean }\end{array}$ & $\begin{array}{c}\text { Daily } \\
\text { change sd }\end{array}$ \\
\hline \multicolumn{7}{|c|}{ Panel (A): Six-month volatility } \\
\hline Volatility for S\&P 500 & 84,849 & 31.1 & 8.3 & 210 & 1.9 & 2.1 \\
\hline Volatility for STOXX 50 & 105,647 & 29.5 & 9.9 & 213 & 1.9 & 2.2 \\
\hline Volatility for DAX & 105,151 & 31.0 & 10.1 & 212 & 1.7 & 1.9 \\
\hline \multicolumn{7}{|c|}{ Panel (B): Three-month volatility } \\
\hline Volatility for S\&P 500 & 84,847 & 31.6 & 10.5 & 210 & 2.8 & 3.4 \\
\hline Volatility for STOXX 50 & 102,171 & 29.8 & 11.9 & 206 & 2.4 & 2.5 \\
\hline Volatility for DAX & 101,663 & 30.0 & 11.7 & 205 & 2.0 & 2.2 \\
\hline \multicolumn{7}{|c|}{ Panel (C): One-month volatility } \\
\hline Volatility for S\&P 500 & 158,843 & 30.2 & 12.8 & 210 & 4.2 & 4.2 \\
\hline Volatility for STOXX 50 & 91,203 & 31.5 & 17.9 & 184 & 4.2 & 4.2 \\
\hline Volatility for DAX & 90,889 & 33.0 & 17.4 & 183 & 4.1 & 4.0 \\
\hline \multicolumn{7}{|c|}{ Panel (D): Stock price indices } \\
\hline S\&P 500 & 85,050 & $3,136.0$ & 284.7 & 210 & 52.3 & 38.4 \\
\hline STOXX 50 & 112,854 & 355.1 & 35.5 & 213 & 6.2 & 4.4 \\
\hline DAX & 110,920 & $12,182.9$ & $1,274.3$ & 212 & 225.0 & 136.0 \\
\hline
\end{tabular}

Sources: Bloomberg; Authors' calculations. ${ }^{10}$

\subsection{Initial Tightening}

In Spring 2020, triggered by the rapidly growing COVID cases, numerous Western countries announced strict nationwide lockdowns. Figure 1 presents the results for the six-month-ahead volatility indices, and the three-month results are available in the Online Appendices (the same comment applies to all the three-month results in subsequent sections unless otherwise stated).

\footnotetext{
10 The same sources apply to all figures and tables in Section 3.
} 
In the figure, the solid black lines are the actual volatility, the solid grey lines are the counterfactuals, and the other two lines are the upper and lower bounds of the $90 \%$ confidence intervals. Take the event of Trump's state-of-emergency declaration as an example. The sixmonth-ahead dropped sharply starting at 3:36 pm on March 13, the exact minute when Trump finished his remarks and started taking questions from the press. ${ }^{11}$ It then dropped by as much as $3.2 \%$ during one minute shortly after that. Moreover, in 15 minutes, it dropped by more than twice the average daily change (about 1.9), from a level of 45 at 3:36 pm to 41 at 3:51 pm. Although this declaration was not a lockdown announcement per se, it signals that the federal government was serious about the situation and that harsh lockdowns by state governments would follow (which indeed happened).

Moreover, such drops lie below the lower bounds of the $90 \%$ confidence intervals of the counterfactual (expected) volatility paths. The same is true for Germany's six-month volatility after its announcement of a historic national lockdown. Even though the actual (expected) volatility was rising, it still lay significantly below the mean counterfactual (which was also rising starting from a much higher level) and below the $90 \%$ confidence interval lower bound. These results suggest that, contrary to the widely-held belief, lockdown announcements may have decreased market participants' perceptions of the six-month-ahead uncertainty.

We would like to make several comments on the methodology. First, in Figure 1, the model used to construct the counterfactual volatility is an $\operatorname{ARIMA}(1,1,1)$ model augmented with two additional predictors: the stock price index itself, and the GARCH-implied volatility. The ARIMA component mainly captures the persistence of historical patterns of volatility, while the stock price and the GARCH components mainly capture new information associated with the announcement. Our "augmented ARIMA approach" is in a similar spirit to the study by Engle and Gallo (2006), which adds a one-month-ahead forecast of MEM-implied volatility to an AR(1) model of VIX (whereas we add time $t$ GARCH-implied actual volatility to an $\operatorname{ARIMA}(1,1,1)$ model of VIX; we use the ex post instead of the ex ante forecasted volatility to enhance the accuracy of the counterfactual). Our approach is also similar to the "factor model" in Fernandes, Medeiros, and Scharth (2014), who forecast the daily-level VIX with S\&P 500 price and volume, an AR(1) component (i.e., last day VIX), and past 5-day, 10-day, 22-day, and 66-day VIX averages. In our case, the "factors" include S\&P 500 price, the ARIMA $(1,1,1)$ components, and a GARCH-implied volatility. Two other counterfactual models are also used, as discussed in the robustness check subsection.

Second, the stock price index itself is used to construct the counterfactual volatility because there are at least four forces associated with a lockdown announcement: (1) The announcement confirms that the outbreak was severe, which tends to decrease stock price and increase (short-

11 The full video for Trump's state of emergency declaration is a vailable here, showing that he finished his remarks at 3 pm 35'40". 
and-medium-term) expected volatility; (2) Other stimulus policies (e.g., fiscal stimulus or monetary easing) may be announced at the same time (or the lockdown announcement signals the severity of the outbreak and makes the market to believe that policymakers will be more likely to pass these stimulus policies), which affects both stock price and expected volatility; (3) The lockdown causes short-term disruptions to the economy, which decreases stock price and increases volatility; (4) The lockdown may have a medium-term economic benefit through containing the outbreak and reducing expected volatility. Controlling for stock price allows us to somewhat proxy for Forces (1)-(3) and test the existence of Force (4), which is the focus of our paper. ${ }^{12}$ Relatedly, it is not obvious that the lower volatility is due to (announced or expected) aggressive monetary easing: such easing could also be seen as the central bank running out of firepower, which tends to increase volatility. For example, on March 15 Sunday, the Fed surprised the market by cutting 125 bps to 0 and launching a massive $\$ 700$ b QE. Some news articles believe this triggered the market's fear that all Fed's firepower had been used and was responsible for the massive stock price declines on March 16 (and may have led to the sharp increases in VIX in the morning of March 16).

Third, we use a 30-minute event window to control for confounding events. Althou gh it appears short, 30 minutes are considered a relatively long window in intraday event study literature (Marshall, Nguyen, and Visaltanachoti, 2017). As McWilliams and Siegel (1997, p. 634) note: "The longer the event window, the more difficult it is for researchers to claim they have controlled for confounding events." In addition, as shown in Chordia, Roll, and Subrahmanyam (2005), among others, new information affecting the stock price is digested by the market within 5-60 minutes.

Fourth, to check whether this substantial drop of volatility is a usual pattern that occurs on most days or truly reflects the impact of the event, we further evaluate the performance of our counterfactual models across the entire sample. Figure 2 plots the average prediction errors of our counterfactual model for the six-month-ahead volatility at the same point of time on each day in our sample, where the prediction error is defined as the actual volatility minus the counterfactual. Across all minutes during our 30-minute event window, the mean prediction errors (for a given minute across all days) are very close to 0 , suggesting that our counterfactual model is broadly unbiased. Moreover, the most negative prediction errors (i.e., the situations where the actual volatility is much lower than the counterfactual) are largely observed on the event days we are

\footnotetext{
12 One may argue that there can be an endogeneity issue: On the one hand, the rapid increa se in COVID cases induces policymakers to impose the lockdown; on the other hand, it also induces more market participants to believe that herd immunity will be achieved sooner due to the higher infections, which in turn tends to lower medium-term volatility. Hence, both the lockdown and the lower medium-term volatility are results of deterioration of COVID dyna mics rather than the former causing the latter. However, very few countries (and market participants) believe that it is effective to achieve herd immunity through more infections. This is evidenced by the harsh criticism of Boris Johnson's earlier remarks and critical views on Sweden's initial "no conta inment" strategy. In addition, the minute-level ana lysis can somewhat mitigate this endogeneity issue.
} 
analyzing (i.e., the prediction errors on the event days fall below the 10th percentiles of the empirical distributions). This result reaffirms that these even ts indeed induced market participants to lower their volatility forecasts relative to the counterfactuals significantly.

Fifth and finally, the VIX (the one-month-ahead volatility index in the US) is widely regarded as the "fear gauge" by financial market participants, and the volatility indices we use are its counterparts for other maturities or in other countries. But to further check the macroeconomic relevance of these indices, we conduct a simple test by regressing the growth rate of the (normalized) purchasing manager index (PMI) on various (lagged) VIX measures. As shown in Table 2, VIX measures are negatively and significantly correlated with the growth rate of the onemonth-ahead PMI, which provides some suggestive evidence that the (forward-looking) volatility indices we use are relevant to the macroeconomy and not just to financial markets. 
Figure 1. Six-Month Volatility Indices (Initial Tightening)

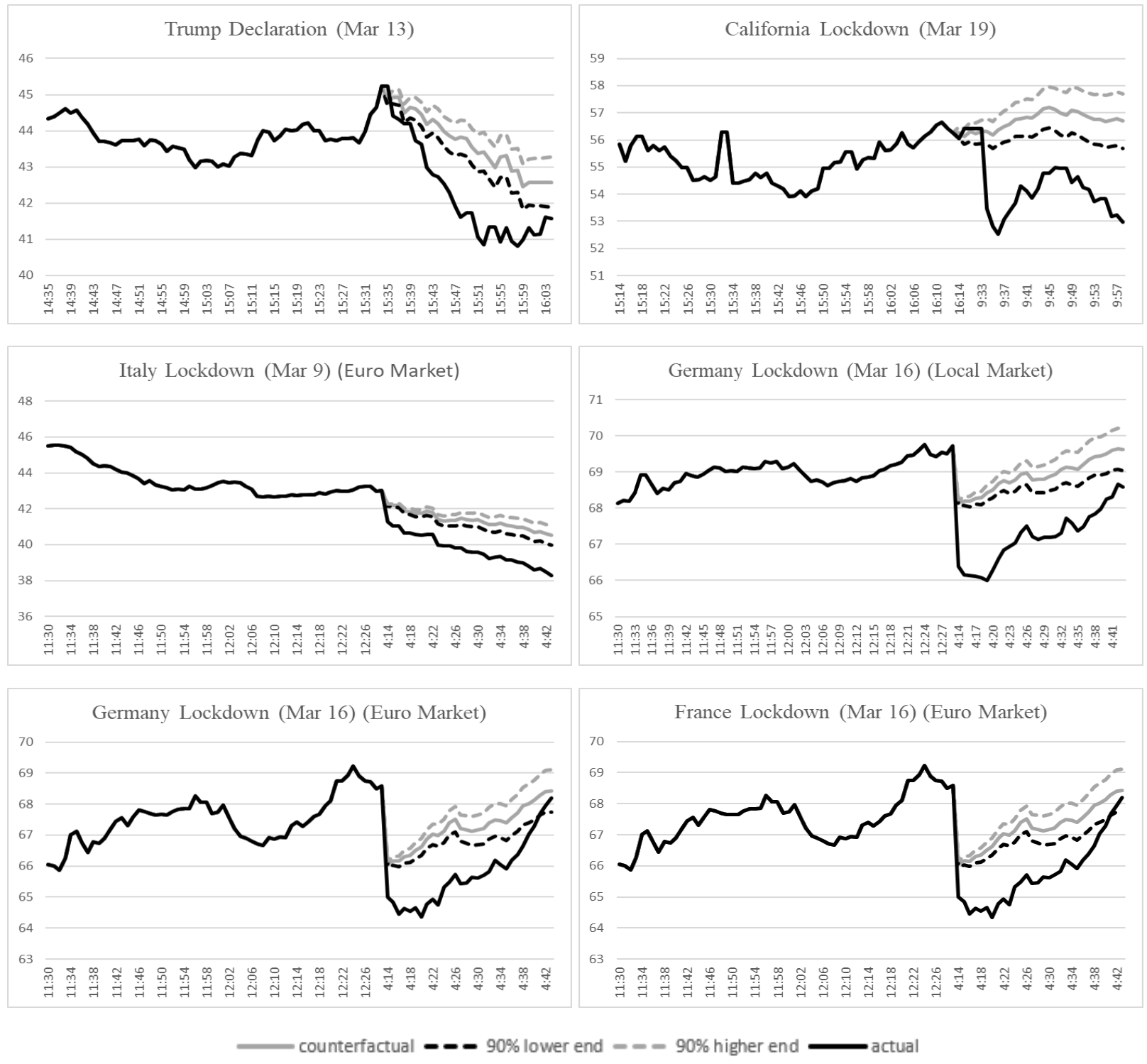


Figure 2. Prediction Errors for Six-Month Volatility Indices (Initial Tightening)

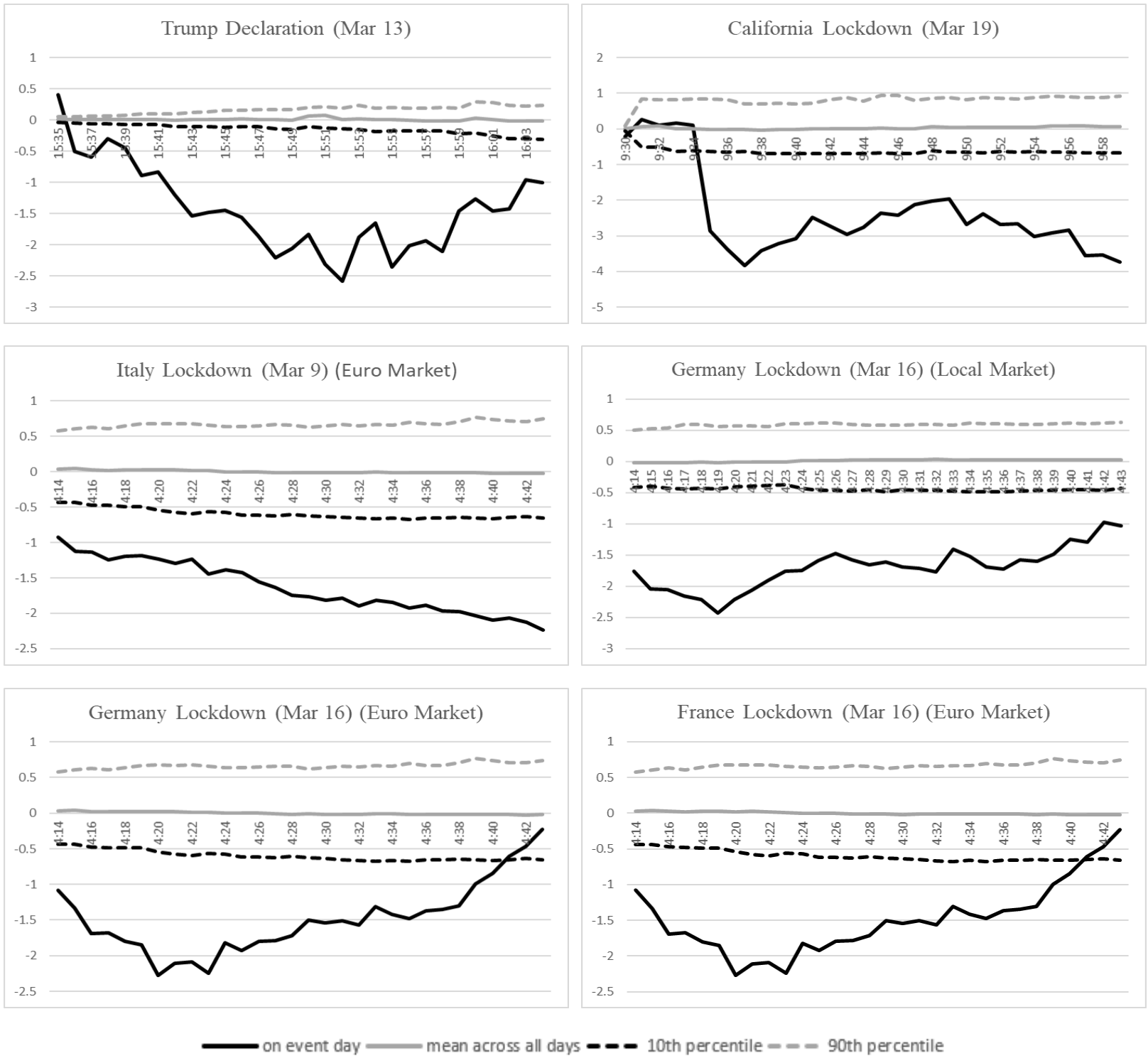


Table 2. Macroeconomic Relevance of Volatility Indices

\begin{tabular}{lcccc}
\hline & $(1)$ & $(2)$ & $(3)$ & $(4)$ \\
& Open & Close & High & Low \\
\hline L.VIX_Open & $-3.368^{* *}$ & & & \\
L.VIX_Close & $(0.026)$ & & & \\
& & $-3.364^{* *}$ & & \\
L.VIX_High & & $(0.027)$ & $-3.201^{* *}$ & \\
& & & $(0.021)$ & \\
L.VIX_Low & & & & $-3.486^{* *}$ \\
& & & & $(0.036)$ \\
Constant & $258.717^{* * *}$ & $258.322^{* * *}$ & $258.872^{* * *}$ & $257.704^{* * *}$ \\
& $(0.000)$ & $(0.000)$ & $(0.000)$ & $(0.000)$ \\
Observations & 119 & 119 & 119 & 119 \\
R-squared & 0.041 & 0.041 & 0.045 & 0.037 \\
\hline
\end{tabular}

Notes: The horizon is Oct 2010 - Sep 2020; $\mathrm{p}$-values are in parentheses: *** $\mathrm{p}<0.01,{ }^{*} \mathrm{p}<0.05,{ }^{*} \mathrm{p}<0.1$.

\subsection{Easing/Reopening}

We now turn to the event studies following the announcements of easing the lockdowns and reopening the economy, mostly in Summer 2020. The results for the six-month-ahead volatility are shown in Figure 3 (three-month results are in the Online Appendices). Since the US does not have a clear-cut easing/reopening date due to its gradual, state-operated reopening (and the difficulty of identifying the precise minute of the first reopening, which was by California), we do not include the US in the event studies for the easing stage.

As shown in Figure 3, for three out of the four events, the six-month-ahead volatility indices did not show statistically different paths from the counterfactuals following the easing announcements. And for the remaining event (Italy's reopening), the six-month-ahead volatility actually rose above the upper bound of the counterfactual's confidence interval. These results are in sharp contrast with conventional wisdom, which suggests that as the stringent containment measures are relaxed, there would be less disruptions to the economy, and thus the uncertainty would also be lower. Therefore, our results provide further suggestive evidence for the existence of the volatility-reducing effect of stringent containment measures emphasized in our paper: although the easing of containment measures provides immediate relief to the economy (which decreases uncertainty), it may raise concerns that the COVID outbreak might recur in the near future (which increases expected volatility). ${ }^{13}$

\footnotetext{
${ }^{13}$ One may argue that the lower volatility may be simply a result of reduced policy uncertainty rather than of the lockdown decision: even if the government instead a nnounced that there would not be any lockdown, the lower policy uncertainty would still lead to lower volatility. It is indeed hard (if not impossible) to empirically rule out this argument because the counterfactual scenario suggested in the comment is not observed by definition. However, the reopening of a n economy can be regarded as a "qua si counterfactual" experiment to test this. The
} 
Figure 3. Six-Month Volatility Indices (Easing)
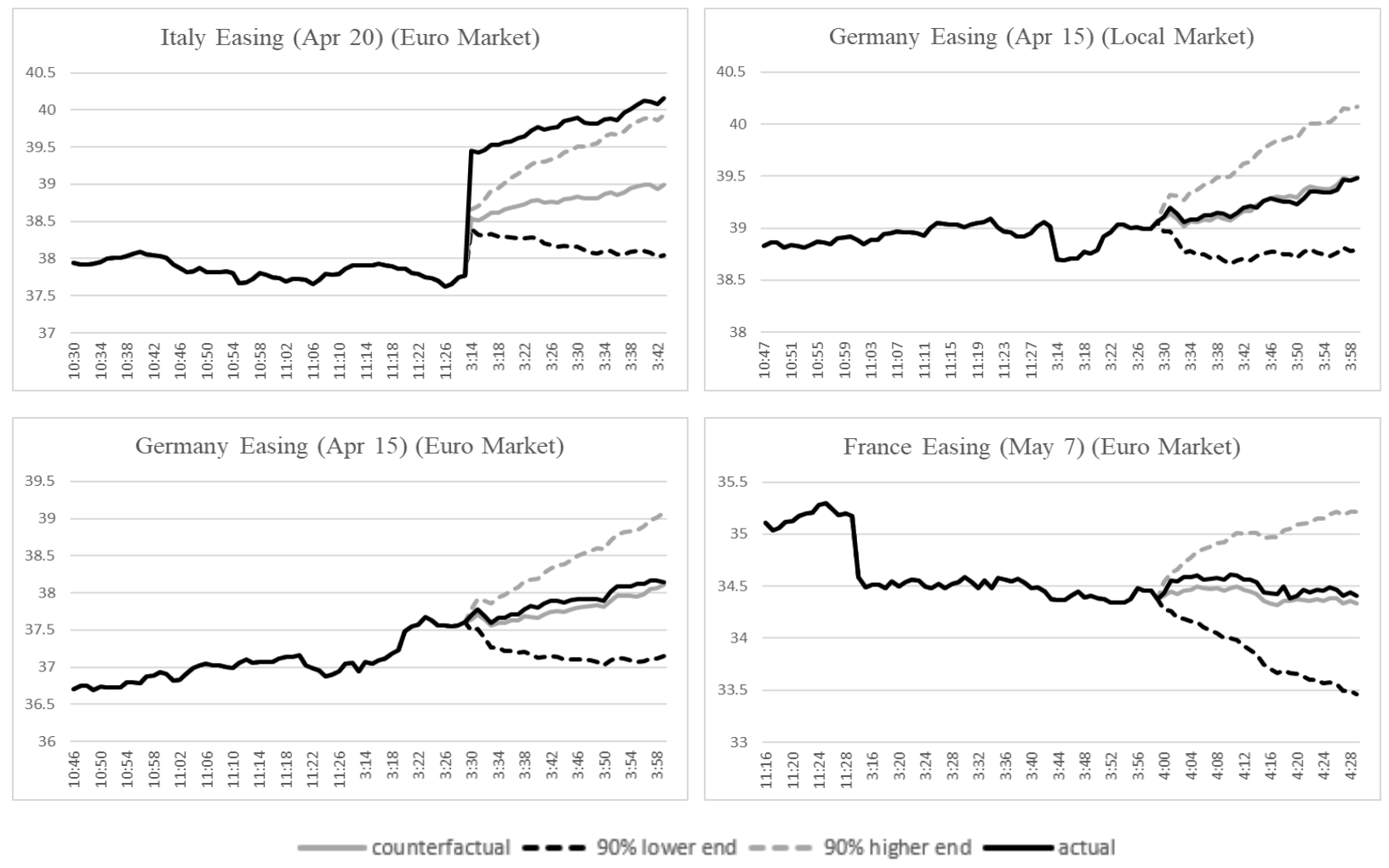

Similar to the case of initial lockdowns, we also evaluate the performance of our counterfactual models across the entire sample. Appendix Figure 1 plots the average prediction errors of our counterfactual model for the six-month-ahead volatility. Across all minutes during our 30-minute event window, the mean prediction errors (for a given minute across all days) are very close to 0 , suggesting that our counterfactual model is also broadly unbiased for the easing stage. However, for three of the four events, the prediction errors on the event day mostly fall between the 10th and 90th percentiles of the empirical distribution of prediction errors across all days, suggesting that the events do not significantly lower the actual volatility relative to the counterfactual. Moreover, for Italy's easing announcement, the prediction errors on the event day are among the top $10 \%$ most positive errors, suggesting that the actual volatility significantly rose above the counterfactual after Italy's easing announcement. These results confirm the results presented in Figure 3.

reopening a nnouncement also lowered policy uncertainty, but this a nnouncement did not lead to lower volatility. As shown in Figure 3, for three out of the four events, the six-month-ahead volatility indices did not show statistically different paths from the counterfactuals; and for the rema ining event (Italy's reopening), the six month-ahead volatility rose above the upper bound of the counterfactual's confidence interv al. 


\subsection{Retightening}

Finally, we discuss the event studies following the retightening announcements recently made in the context of new COVID waves. The results for the six-month-ahead expected volatility are shown in Figure 4. Also, because the US does not have a clear-cut retightening date yet, we do not include the US in the event studies for the retightening stage.

As shown in Figure 4, following Germany's retightening announcement around Eastern Time 11:35 am on October 28, the local and eurozone-wide expected volatility indices were significantly lower than the counterfactuals, with a significance level close to $10 \%$ (the actual paths almost overlapped the lower bounds of the counterfactuals' $90 \%$ confidence intervals). A similar pattern was observed following France's retightening announcement on the night of October 28, although the actual (expected) volatility was only significantly lower than the counterfactual for the first 19 minutes in the 30-minute event window and then rose to inside the $90 \%$ confidence interval.

The case of Italy's retightening announcement on the night of October 25 appears to display a more mixed pattern: expected volatility was slightly above the upper bound of the $90 \%$ confidence interval for the first 10 minutes and then dropped to inside the confidence interval. In addition, the average prediction errors (Appendix Figure 2 for six-month-ahead volatility) suggest that the deviations of the actual volatility from the counterfactuals on Italy's retightening day were within the range of the $10 \%$ and $90 \%$ percentiles of the empirical distribution across all days. Hence, Italy's retightening announcement was followed by neither a significantly higher nor lower volatility relative to the counterfactuals.

In sum, during the retightening stage, event studies show that the announcements of reimposing lockdowns are still followed by somewhat significantly lower volatility, similar to the initial lockdowns. However, the statistical significance is lower than the initial tightening stage. There are multiple interpretations of these results. One interpretation is that they reflect market participants' perception that the governments' containment measures during the retighte ning stage are less stringent than the initial stage, which may be inadequate to contain the second waves and thus, volatility did not drop as much.

\section{Figure 4. Six-Month Volatility Indices (Retightening)}
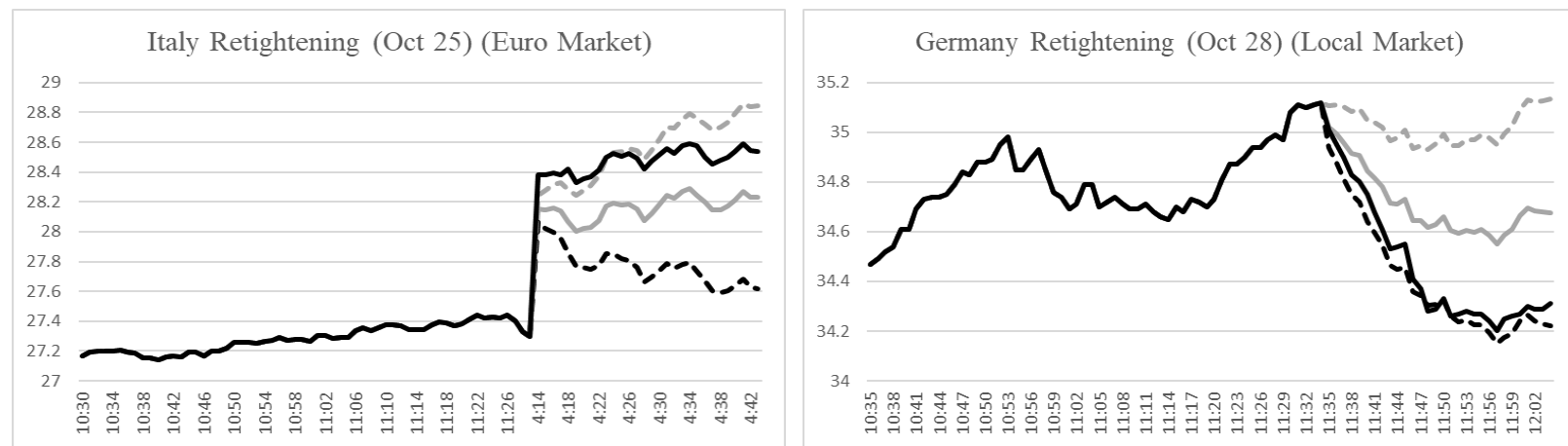


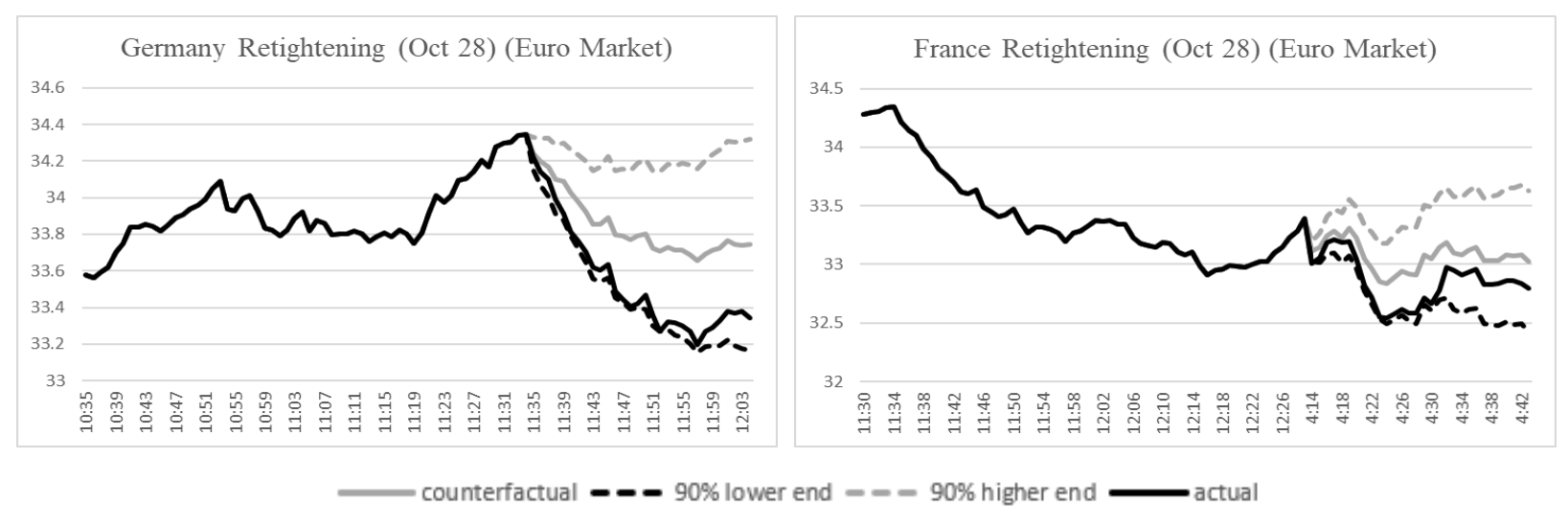

\subsection{Monotonicity Over Time}

To shed more light on the intertemporal trade-off explained in the Introduction, we compare the responses of volatility indices across different maturities, i.e., the one-month-, three-month-, and six-month-ahead volatility indices. To ensure comparability, we use the same counterfactual model for all maturities, that is, an $\operatorname{ARIMA}(1,1,1)$ model augmented with the stock price index and the GARCH-implied volatility.

Figure 5 presents the comparison result following Germany's initial tightening on March 16,2020 (for the volatility of its domestic stock index). As shown in the top left chart, the onemonth-ahead volatility index actually jumped above the upper bound of the $90 \%$ confidence interval during the first half of the event window before falling within the interval. By contrast, the three-month-ahead volatility index dropped below the lower bound of the $90 \%$ confidence interval during the first half before falling within the interval, suggesting that the lockdown announcement significantly decreased the three-month-ahead volatility. The most significant response is displayed in the bottom left chart, where the six-month-ahead volatility index stayed below the lower bound of the $90 \%$ confidence interval throughout the entire event window. This monotonicity is confirmed by the three right-hand-side charts in Figure 5, which plot the prediction errors of the counterfactual model for the three maturities.

A similar pattern is observed following France's initial tightening on March 16, 2020 (Figure 6), Italy's initial tightening on March 9, 2020 (Appendix Figure 3), and Germany's retightening on October 28, 2020 (also for the volatility of its domestic stock index, Figure 7). For some other events studied in previous sections, including Trump's state-of-emergency declaration and California's initial lockdown during the initial tightening stage, the one-month-ahead volatility is still significantly lower after the announcement. ${ }^{14}$

\footnotetext{
${ }^{14}$ Note that because the responses of volatility indices during the ea sing stage are not statistically significant, we do not compare the responses a cross different maturities.
} 
In summary, we find suggestive evidence that that the results presented in previous sections are the strongest for six-month-ahead expected volatility; not as strong for three-month-ahead expected volatility; and generally absent for one-month-ahead expected volatility. This monotonicity provides suggestive evidence for the existence of the intertemporal trade-off associated with lockdown: The lockdown disrupts the economy, which increases volatility; But it contains the COVID outbreak, which decreases volatility. Both of these two forces are present not only in the medium term (six months) but also in the short term (one month). In general, the volatility-decreasing effect is more likely to dominate the volatility-increasing effect in the medium term, as suggested by the finding in this section. Although we do not study the volatility beyond the six-month horizon due to data limitations, the increasing significance of results over time seems informative.

Then how to explain the results where the one-month-ahead volatility is still significantly lower after the lockdown? The answer again lies in the intertemporal trade-off: since the observed volatility is a result of two countervailing forces, it is still possible that in some countries and for some events, the volatility-decreasing effect can already dominate the volatility-increasing effect even in the short term.

\subsection{Robustness checks}

To further validate our results, we conduct three sets of robustness checks. First, while constructing the counterfactual volatility, we drop the GARCH-implied volatility from the list of predictors. That is, we use an ARIMA model augmented with the stock price index as the only additional predictor. The results for six-month-ahead volatility are presented in Appendix Figures 3-5, with one figure for one stage (initial tightening, easing, and retightening). All results a re very similar to the main results discussed above. Note that the alternative counterfactual models' empirical prediction error bands are not constructed due to the heavy computation burden (the construction for each event takes more than 5 hours).

Second, we replace the GARCH-implied volatility with the EGARCH-implied volatility in the counterfactual models. That is, we use an ARIMA model augmented with the stock price index and EGARCH-implied volatility as two additional predictors. The results are presented in Appendix Figures 6-8, with one figure for one stage.

Third, since the six-month-ahead volatility index overlaps the three-month-ahead volatility index for the first three months, we further decompose each index into non-overlapping indices. That is, we decompose the six-month-ahead volatility index into the three-month-ahead volatility and the volatility from Month 3 to Month 6. We then repeat the event studies for the initial tightening, easing, and retightening stages using these non-overlapping volatility indices as the dependent variables. The results are available in the Online Appendices. All results in these robustness checks are very similar to the main results discussed above. 
Figure 5. Volatility Responses Across Maturities: Germany's Initial Tightening (Local Market)
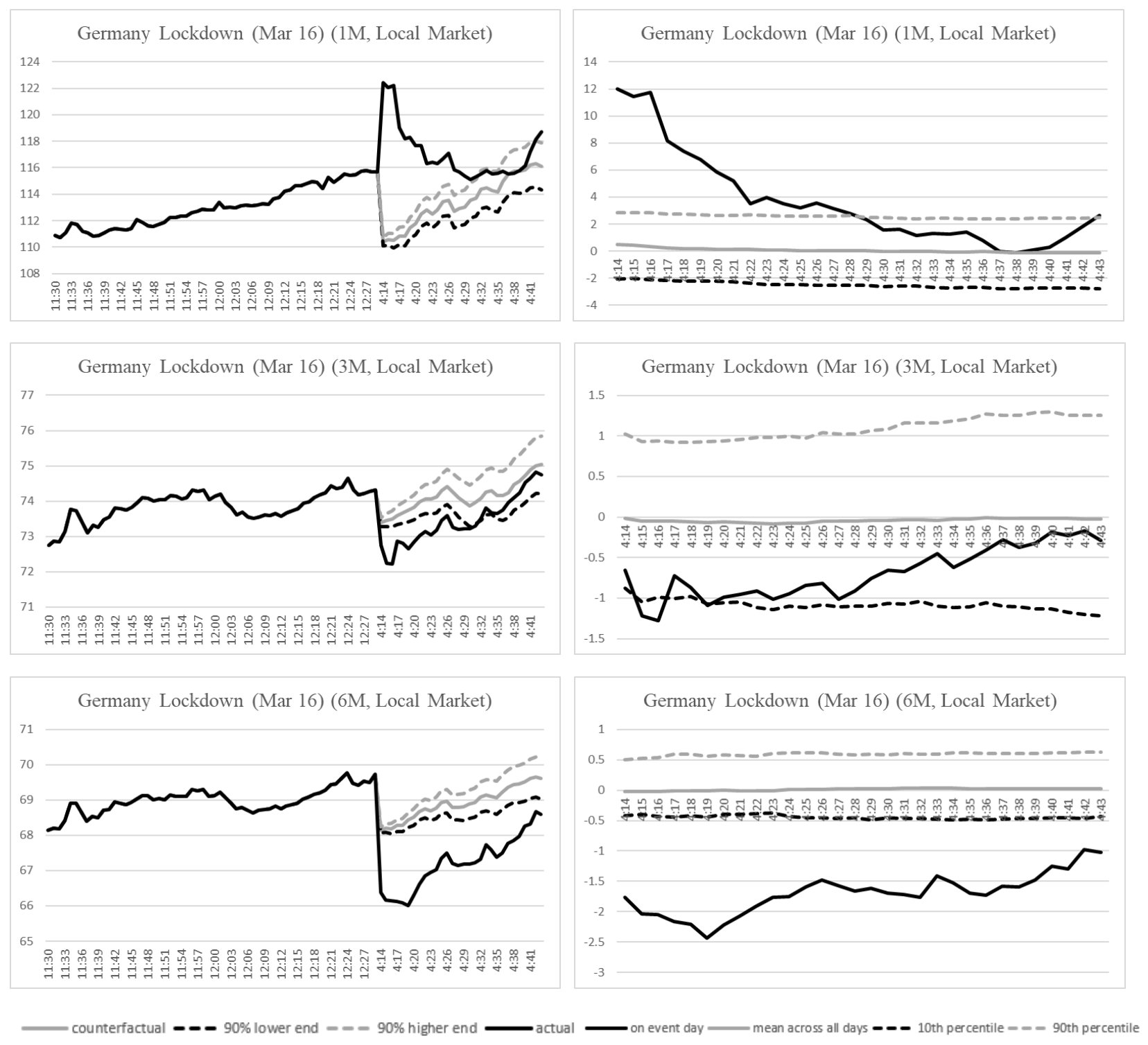
Figure 6. Volatility Responses Across Maturities: France's Initial Tightening
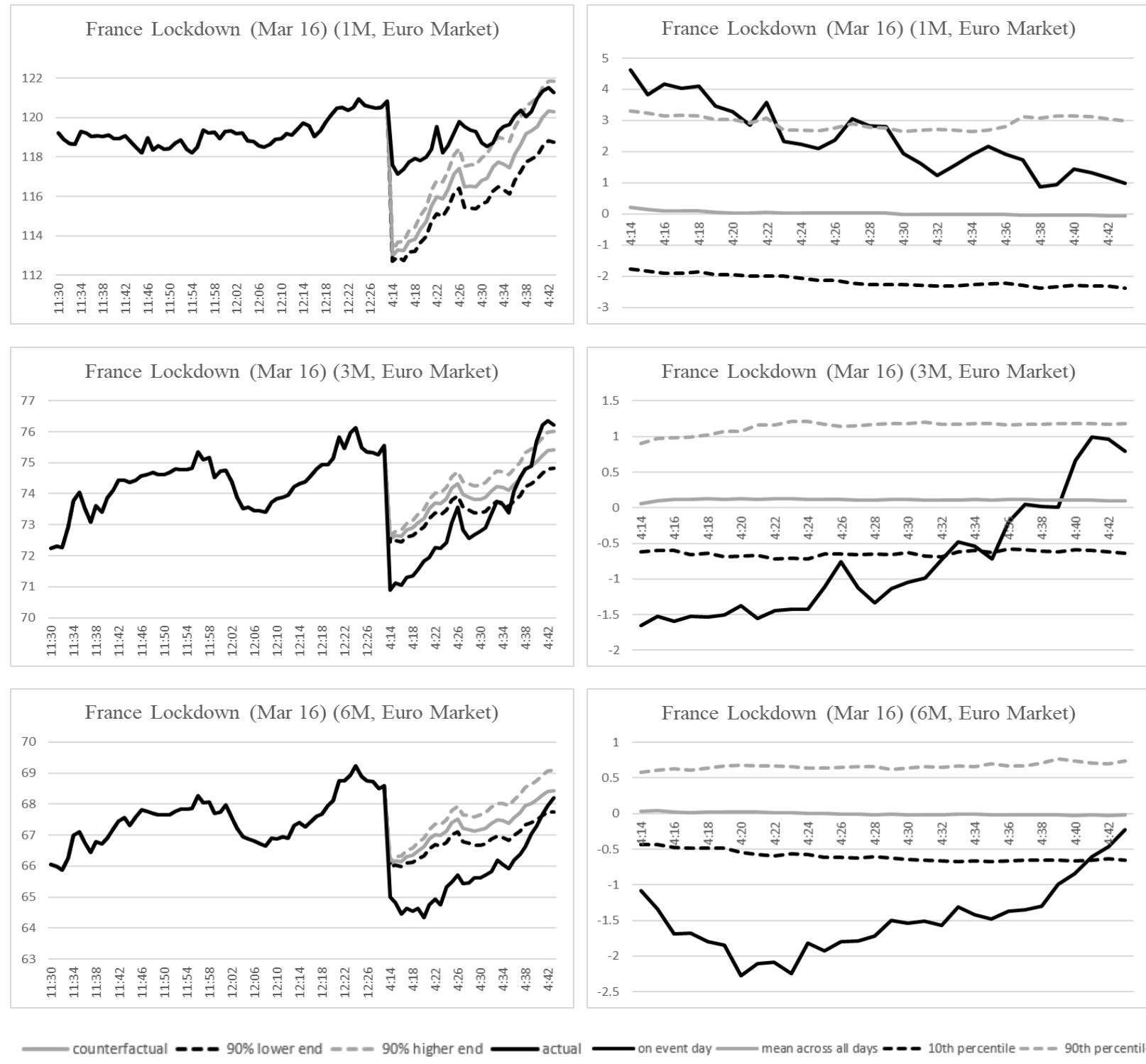

$$
\text { France Lockdown (Mar 16) (6M, Euro Market) }
$$
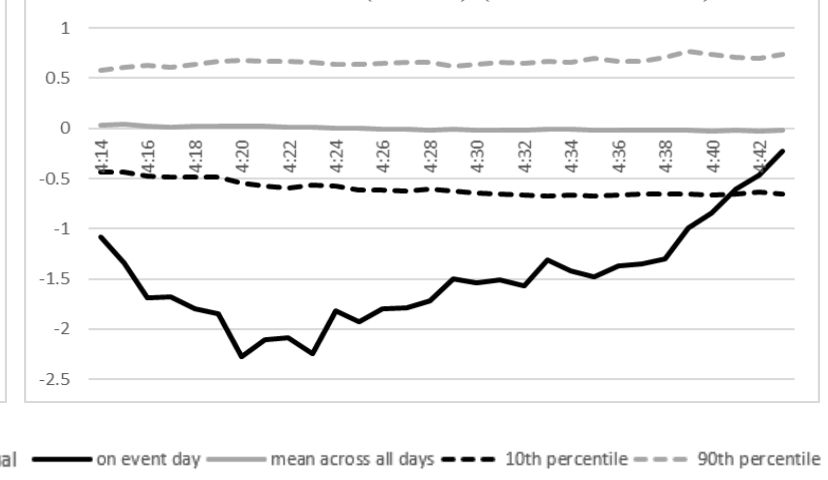
Figure 7. Volatility Responses Across Maturities: Germany's Retightening (Local Market)
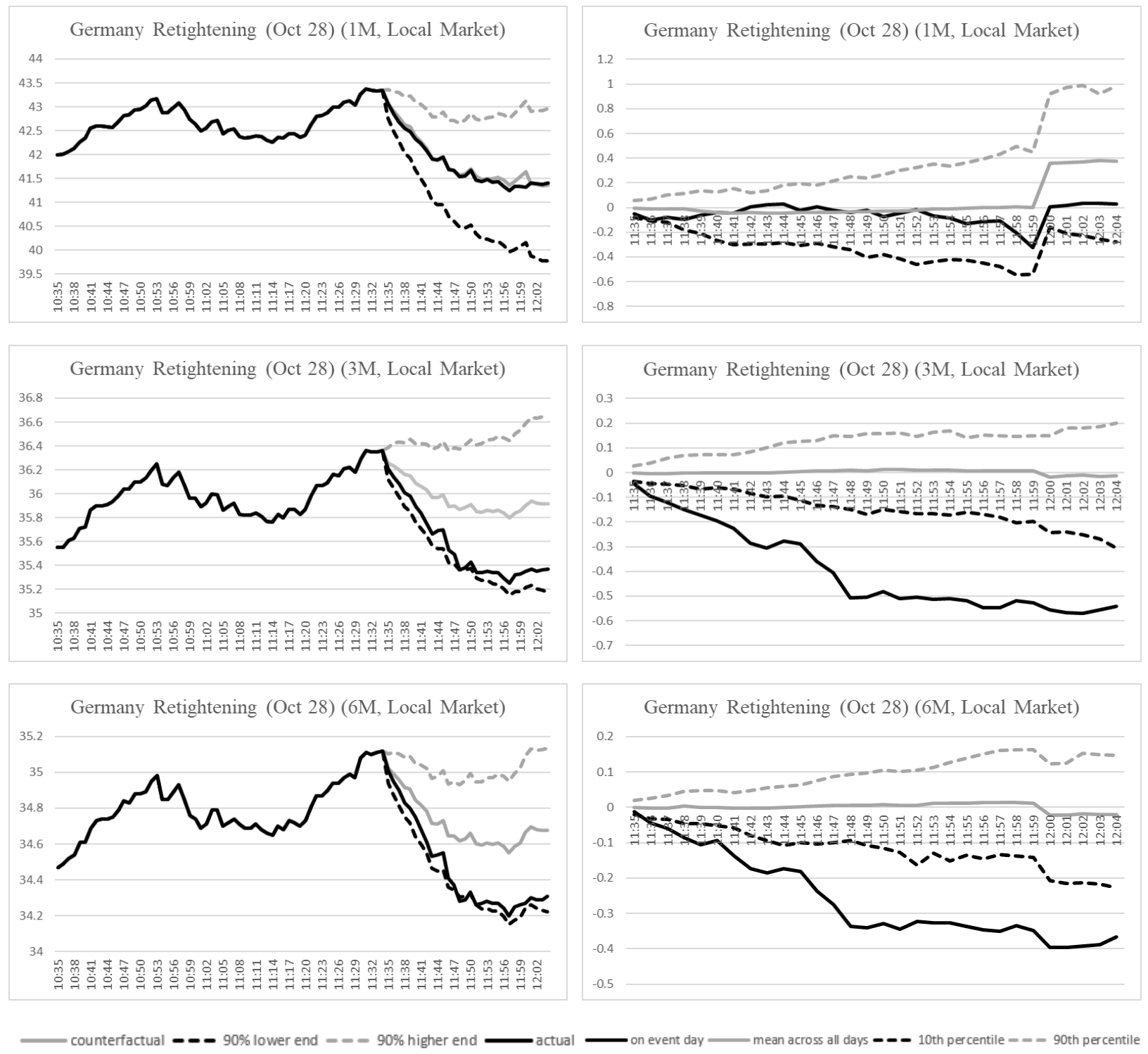

\section{$4 \quad$ Regressions with Daily Data}

\subsection{Data}

The daily data used in the regression approach cover weekdays from January 3, 2020 to October 22,2020 , including the initial tightening, easing, and retightening stages. Due to limitations on the expected volatility data, the following five countries/regions are covered: the US, Italy, Germany, Euro Area, and the UK. Note that, unlike the event study approach, the regression approach uses the country-specific volatility index for Italy instead of the eurozone-wide volatility because the daily data for this volatility index is available. For the same reason, the UK is covered in the 
regression approach, even though it is not in the event study approach. However, because France still does not have the daily data for its country-specific volatility index beyond the one-month horizon, it is not covered in the regression approach.

Daily data on the stringency index are from the widely-used Oxford COVID-19 Government Response Tracker (OxCGRT) database. The index provides a continuous measurement of the stringency of COVID containment and closure policies. It scales between 0 and 100, with 100 representing the most stringent measures. It is constructed based on eight indicators, including school closing, workplace closing, public events cancellation, restrictions on gatherings, public transport closure, stay-at-home requirements, restrictionson internal movement, and international travel controls. ${ }^{15}$ The same dataset also provides COVID case numbers. The stock price data are from Bloomberg.

The summary statistics are presented in Appendix Table 1 for each of the three stages. Note that rescaling is done to make the displayed coefficients more informative. Because of this, the units of the volatility percent change and of the stock price percent change are basis points (i.e., $1 / 100$ percent), although the units of the COVID case percent change and stringency index remain as the percent. However, it can be shown that the interpretation of economic significance is invariant to the units of the variables and thus is not affected by the rescaling.

\subsection{Initial Tightening}

For each stage (initial tightening, easing, and retightening), we first conduct the regressions for the benchmark models that include stringency index, COVID case growth rate, and the interaction of the two as the only regressors (along with the constant term). We then add the stock price percent change (and its lag) and re-run the regressions. Finally, we obtain the "full" models after adding the intraday standard deviation of the stock price (and its lag) to capture forces that affect the current realized volatility (note that the dependent variables in the regressions are forward-looking expected volatility). The data samples used for the regressions in each stage are unbalanced panel datasets because different countries have different easing/reopening and retightening days, but all countries start the data from January 3, 2020 for the initial tightening stage.

The benchmark model results for the initial tightening stage are presented in Appendix Table 2 (only results for six-month volatility are shown; those for three-month are available in the Online Appendices). As the table shows, the interaction term is not statistically significant. However, the stringency index itself is statistically significant and negatively correlated with the percent changes of volatility, consistent with our main idea that containment measures help reduce uncertainties. Note that the R-squared's are low in the benchmark models, suggesting the possible existence of omitted variable bias.

${ }^{15}$ More details are available here. 
We then add the stock price percent change (and its lag). The results for the initial tightening stage are presented in Appendix Table 3. Now the stringency index itself becomes insignificant, and the interaction term becomes significantly negative, suggesting that the containment measures reduce expected volatility through the interaction with the outbreak dynamics. Importantly, the stock price percent change is highly significant, and the R-squared's have improved significantly, confirming the existence of omitted variable bias in the benchmark models.

Finally, we obtain the regression results for the initial tightening stage in the full models that include the intraday standard deviation of the stock price (and its lag). The results are presented in Table 3, which are similar to those in the models with stock price percent change. Specifically, we would like to highlight the following:

First, the stringency index itself is insignificant, and the interaction term is significantly negative. This implies that (a) the marginal effect of stringency index on expected volatility (equal to the coefficient of the interaction term, multiplied by the COVID case growth rate) is still negative, as the COVID case growth rate is positive; (b) containment measures reduce volatility mainly through the interaction with the outbreak dynamics - the more severe the outbreak is, the stronger this effect is; (c) containment measures mitigate the volatility-increasing effect of the COVID case growth, ${ }^{16}$ as illustrated in Figure 8: when the stringency index is low (equal to the sample mean minus one standard deviation), a higher COVID case growth is associated with a higher expected volatility (the dash line); but as the stringency index increases, e.g., to the sample mean (the solid line) or the sample mean plus one standard deviation (the dash-dot line), the volatility-increasing effect of COVID case growth is mitigated and ultimately reversed, possibly because the stringent containment measures have reduced infections and generated indirect economic benefit.

\footnotetext{
${ }^{16}$ Note that the marginaleffect on volatility equals the positive coefficient of the COVID case growth, plus the product of the negative coefficient of the interaction term and the (positive) stringency index. Hence, the COVID case growth has a positive marginaleffect on volatility if the stringency index equals 0 .
} 
Figure 8. Interaction Between Stringent Containment Measures and COVID Case Growth

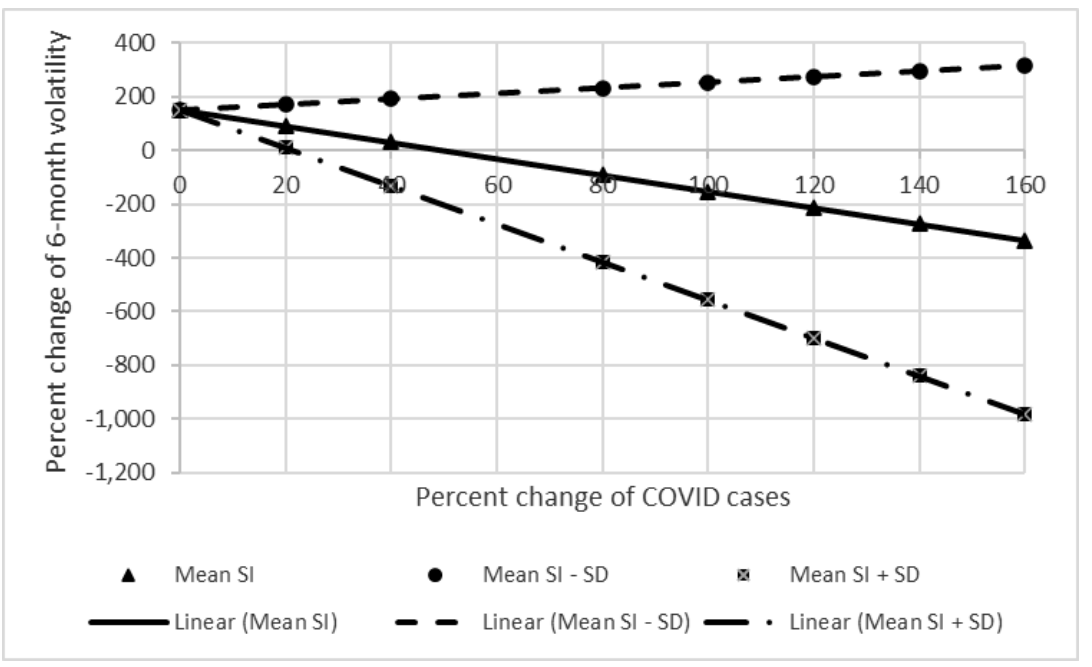

Note: SI = Stringency Index; All other regressors are evaluated at respective sample means.

Sources: Oxford; Authors' calculations. ${ }^{17}$

Second, as expected, the percent change of the stock price index is negatively correlated with both volatility indices in all specifications and acts as a control for other forces that drive the volatility. As for the standard deviation of the stock price, the lagged term is positively correlated with volatility, and the current term is negatively correlated. This seemingly counterintuitive result may be because the standard deviation is unable to capture the direction of stock price movementa high standard deviation could mean either an increase in stock price (in which case volatility tends to be low) or a decrease in stock price (in which case volatility tends to be high). ${ }^{18}$

Third, the economic significance of the interaction term (in italic) has the same order of magnitude as the stock price percent change. This reassures that the stringency index is as economically relevant as other forces (captured by the stock price percent change) in driving the expected volatility.

\section{Table 3. Initial Tightening Stage Panel Regressions in the Full Model}

\begin{tabular}{|c|c|c|c|c|c|c|}
\hline & (1) & (2) & (3) & (4) & (5) & (6) \\
\hline & SI & Cases & Interaction & SI & Cases & Interaction \\
\hline & $\mathrm{FE}$ & $\mathrm{FE}$ & $\mathrm{FE}$ & $\mathrm{RE}$ & $\mathrm{RE}$ & RE \\
\hline \multirow[t]{2}{*}{ StringencyIndex } & $-1.819 * *$ & & -0.527 & $-1.557^{*}$ & & -0.242 \\
\hline & $(0.032)$ & & $(0.559)$ & $(0.065)$ & & $(0.788)$ \\
\hline
\end{tabular}




\begin{tabular}{|c|c|c|c|c|c|c|}
\hline & & $\begin{array}{l}-0.181 \\
(0.817)\end{array}$ & $\begin{array}{c}1.731 * \\
(0.063)\end{array}$ & & $\begin{array}{c}0.132 \\
(0.866)\end{array}$ & $\begin{array}{c}2.032 * * \\
(0.029)\end{array}$ \\
\hline Cases_pct_SI & & & $\begin{array}{c}-0.114 * * * \\
(0.000)\end{array}$ & & & $\begin{array}{c}-0.112 * * * \\
(0.000)\end{array}$ \\
\hline StockPrice_pct & $\begin{array}{c}-1.849 * * * \\
(0.000)\end{array}$ & $\begin{array}{c}-1.883 * * * \\
(0.000)\end{array}$ & $\begin{array}{c}-0.182 \\
-1.919 * * * \\
(0.000)\end{array}$ & $\begin{array}{c}-1.874 * * * \\
(0.000)\end{array}$ & $\begin{array}{c}-1.894 * * * \\
(0.000)\end{array}$ & $\begin{array}{c}-0.179 \\
-1.933 * * * \\
(0.000)\end{array}$ \\
\hline Lag_StockPrice_pct & $\begin{array}{c}0.247 * * \\
(0.013)\end{array}$ & $\begin{array}{c}0.207 * * \\
(0.039)\end{array}$ & $\begin{array}{c}-0.718 \\
0.197 * * \\
(0.048)\end{array}$ & $\begin{array}{c}0.199 * * \\
(0.043)\end{array}$ & $\begin{array}{l}0.173 * \\
(0.082)\end{array}$ & $\begin{array}{c}-0.723 \\
0.156 \\
(0.117)\end{array}$ \\
\hline StockPrice_std & $\begin{array}{c}-2.165 * * * \\
(0.000)\end{array}$ & $\begin{array}{c}-2.385 * * * \\
(0.000)\end{array}$ & $\begin{array}{c}-2.007 * * * \\
(0.001)\end{array}$ & $\begin{array}{c}-2.780 * * * \\
(0.000)\end{array}$ & $\begin{array}{c}-2.930 * * * \\
(0.000)\end{array}$ & $\begin{array}{c}-2.639 * * * \\
(0.000)\end{array}$ \\
\hline Lag_StockPrice_std & $\begin{array}{c}4.260 * * * \\
(0.000)\end{array}$ & $\begin{array}{c}4.085^{* * *} \\
(0.000)\end{array}$ & $\begin{array}{c}4.410 * * * \\
(0.000)\end{array}$ & $\begin{array}{c}3.694 * * * \\
(0.000)\end{array}$ & $\begin{array}{c}3.561 * * * \\
(0.000)\end{array}$ & $\begin{array}{c}3.802 * * * \\
(0.000)\end{array}$ \\
\hline Observations & 396 & 396 & 396 & 396 & 396 & 396 \\
\hline R-squared & 0.532 & 0.526 & 0.550 & & & \\
\hline
\end{tabular}

Notes: (1) p-values are in parentheses. (2) FE = fixed effect; $\mathrm{RE}=$ random effect.

\subsection{Easing/Reopening}

The cutoff dates for the easing stage regressions are determined based on the Oxford stringency index. Note that to provide a comparison benchmark and obtain a sharper identification, the starting date used in the easing stage regressions is a few working days earlier than the actual easing/reopening day. For example, the stringency index shows that Germany eased on May 4, 2020, but we start the sample for Germany's easing stage regressions from April 24.

Regressions for the easing stage from the benchmark models and models with stock price percent change are also conducted, but the results are omitted for brevity. ${ }^{19}$ Similar to the initial tightening stage, the addition of stock price percent change (and its lag) also substantially increases the R-squared's. The results from the full models for the easing stage are presented in Panel(A) of Table 4, where the results on the lagged stock price percent change, the stock price standard deviation, and its lag are not reported.

${ }^{19}$ These results are available upon request. 
Table 4. Panel Regressions in the Full Model: Easing and Retightening Stages

\begin{tabular}{|c|c|c|c|c|c|c|}
\hline & $\begin{array}{l}(1) \\
\text { SI } \\
\text { FE }\end{array}$ & $\begin{array}{c}(2) \\
\text { Cases } \\
\text { FE } \\
\end{array}$ & $\begin{array}{c}(3) \\
\text { Interaction } \\
\text { FE } \\
\end{array}$ & $\begin{array}{l}(4) \\
\text { SI } \\
\text { RE }\end{array}$ & $\begin{array}{c}(5) \\
\text { Cases } \\
\text { RE }\end{array}$ & $\begin{array}{c}(6) \\
\text { Interaction } \\
\text { RE } \\
\end{array}$ \\
\hline \multicolumn{7}{|c|}{ Panel (A): Easing stage } \\
\hline StringencyIndex & $\begin{array}{l}-3.374 \\
(0.124)\end{array}$ & & $\begin{array}{l}-4.461 \\
(0.138)\end{array}$ & $\begin{array}{l}-3.015 \\
(0.110)\end{array}$ & & $\begin{array}{l}-3.166 \\
(0.216)\end{array}$ \\
\hline Cases_pct & & $\begin{array}{l}-24.827 \\
(0.174)\end{array}$ & $\begin{array}{c}-193.858 \\
(0.310)\end{array}$ & & $\begin{array}{l}-22.657 \\
(0.166)\end{array}$ & $\begin{array}{c}-108.048 \\
(0.528)\end{array}$ \\
\hline Cases_pct_SI & & & $\begin{array}{c}2.483 \\
(0.353)\end{array}$ & & & $\begin{array}{c}1.335 \\
(0.583)\end{array}$ \\
\hline StockPrice_pct & $\begin{array}{c}-2.023 * * * \\
(0.000)\end{array}$ & $\begin{array}{c}-2.018 * * * \\
(0.000)\end{array}$ & $\begin{array}{c}-2.026 * * * \\
(0.000)\end{array}$ & $\begin{array}{c}-2.026 * * * \\
(0.000)\end{array}$ & $\begin{array}{c}-2.020 * * * \\
(0.000)\end{array}$ & $\begin{array}{c}-2.029 * * * \\
(0.000)\end{array}$ \\
\hline Observations & 257 & 257 & 257 & 257 & 257 & 257 \\
\hline R-squared & 0.598 & 0.597 & 0.600 & & & \\
\hline \multicolumn{7}{|c|}{ Panel (B): Retightening stage } \\
\hline StringencyIndex & $\begin{array}{c}2.890 \\
(0.424)\end{array}$ & & $\begin{array}{c}5.875 \\
(0.125)\end{array}$ & $\begin{array}{l}-0.534 \\
(0.684)\end{array}$ & & $\begin{array}{c}2.903 \\
(0.136)\end{array}$ \\
\hline Cases_pct & & $\begin{array}{c}2.299 \\
(0.778)\end{array}$ & $\begin{array}{c}128.279 * * \\
(0.022)\end{array}$ & & $\begin{array}{c}3.033 \\
(0.705)\end{array}$ & $\begin{array}{c}130.986 * * \\
(0.017)\end{array}$ \\
\hline Cases_pct_SI & & & $\begin{array}{c}-2.159 * * \\
(0.024) \\
-0.652\end{array}$ & & & $\begin{array}{c}-2.206 * * \\
(0.018) \\
-0.666\end{array}$ \\
\hline StockPrice_pct & $\begin{array}{c}-1.729 * * * \\
(0.000)\end{array}$ & $\begin{array}{c}-1.719 * * * \\
(0.000)\end{array}$ & $\begin{array}{c}-1.720 * * * \\
(0.000) \\
-0.520\end{array}$ & $\begin{array}{c}-1.718 * * * \\
(0.000)\end{array}$ & $\begin{array}{c}-1.718^{* * *} \\
(0.000)\end{array}$ & $\begin{array}{c}-1.707 * * * \\
(0.000) \\
-0.516\end{array}$ \\
\hline Observations & 289 & 289 & 289 & 289 & 289 & 289 \\
\hline R-squared & 0.538 & 0.537 & 0.547 & & & \\
\hline
\end{tabular}

Notes: (1) p-values are in parentheses. (2) $\mathrm{FE}=$ fixed effect; $\mathrm{RE}=$ random effect.

As in the initial tightening stage, the stock price percent change is negatively correlated with expected volatility, and the effect is highly significant during the easing stage. A major difference is that during the easing stage, neither the containment measures nor their interactions with the COVID case growth are statistically significant, which suggests that the easing of stringent containment measures is not associated with a significant reduction in volatility. Conventional wisdom is that as the stringent containment measures are relaxed, there would be less disruptions to the economy, and thus the expected volatility and uncertainty would also be 
lower. However, similar to the event study results, our regression results do not support this hypothesis. This, in turn, provides further suggestive evidence for the existence of the trade-off emphasized in our paper: although the easing of containment measures provides immediate relief to the economy (hence decreasing uncertainty perceived by the market), it may raise concerns that the COVID outbreak might recur in the near future (hence increasing uncertainty).

\subsection{Retightening}

The cutoff dates for the retightening stage regressions are generally determined based on the Oxford stringency index. But to obtain a sharper identification, in some cases we again skip the long "post-easing" period when the stringency index remained flat and low. For example, even though we end Italy's easing stage on June 10, we skip the data in the next two months for Italy due to its flat and low stringency index; instead, we start Italy's retightening stage on August 11, which is five weekdays before Italy publicly announced a reintroduction of restrictions on August 17 (see the announcement here; we include the five extra weekdays to provide a comparison benchmark). Note that although the stringency index for the US did not show a retightening after its easing stage, we still include the US in the regression as a benchmark to help identify the effect of retightening by other countries.

Regressions for the retightening stage from the benchmark models and models with stock price percent change are also conducted, but the results are omitted for brevity. ${ }^{20}$ Similar to the initial tightening stage and the easing stage, the addition of stock price percent change also substantially increases the R-squared's. The results from the full models for the retightening stage are presented in Panel (B) of Table 4.

As in the other two stages, the stock price percent change is negatively correlated with volatility, and the effect is highly significant during the retightening stage. A major finding is that during the retightening stage, more stringent containment measures are again associated with lower volatility, although its statistical significance is lower than the initial tightening stage. Specifically, for the six-month volatility, the p-values for the interaction term between stringency index and COVID case growth are around 2 percent in the retightening stage, compared with 0 percent in the initial tightening. And for three-month results (available in the Online Appendices), the p-values for the interaction term are above 20 percent in the retightening stage, compared with 1-2 percent in the initial tightening.

As discussed in the event study results, one interpretation is that these results reflect market participants' perception that the governments' containment measures during the retightening stage are less stringent than the initial stage, which may be perceived as inadequate to contain the second waves. As a result, volatility did not drop as much as in the initial tightening stage.

20 These results are a vailable upon request. 


\subsection{Robustness checks}

In addition to the various models presented above, we conduct two more sets of robustness checks. First, given that COVID-19 is a global shock that affects different countries and different volatility products, we conduct seemingly unrelated regressions (SUR) to account for the correlations among countries and volatility products. Doing so would require a balanced panel dataset, so we conduct the SUR for the whole sample only, without distinguishing among different stages (recall that different countries have different reopening and retightening dates, so distinguishing among different stages would result in unbalanced panel datasets). The results are presented in Appendix Table 3, which are very similar to the full model results during the initial tightening stage.

Second, as with the event studies, we also decompose each volatility index into nonoverlapping indices. Specifically, we decompose the six-month-ahead volatility index into the volatility from the three-month-ahead volatility and the volatility from Month 3 to Month 6 . We then repeat the regressions for the initial tightening, easing, and retightening stages using these non-overlapping volatility indices as the dependent variables (for the full models). The results are available in the Online Appendices, which are again similar to the results in the corresponding stage.

\section{$5 \quad$ Conclusion and Policy Implications}

Using event studies with minute-level expected volatility data and panel regressions with daily data, we empirically show that COVID containment measures reduce six-month-ahead expected stock price volatility indices. This pattern is not as strong for the three-month-ahead expected volatility and generally absent for the one-month-ahead expected volatility. Our results provide some suggestive evidence that such measures may have an economic benefit of reducing mediumterm uncertainty despite their short-term economic disruptions.

Future studies can explore further the channel through which containment measures reduce the expected volatility. To this end, one could analyze the responses of volatility in different sectors. If the contact-intensive sectors experienced a significantly larger drop in volatility, then this supports a real economy channel: containment measures would put the pandemic under control, which would be more beneficial to the contact-intensive sectors, leading to lower volatility in these sectors than in other sectors. Another caveat is that, due to data limitations, the number of events we study is relatively small, with an exclusive focus on advanced economies. Future studies can apply event studies to other measures of uncertainty or confidence in other types of economies, possibly at a daily or weekly frequency, given that it is hard to find minute-level data. Finally, since vaccination is also one containment measure, it is worth exploring the impact of positive vaccine-related news on the expected volatility.

Our results have some potential policy implications. First, on containment and reopening strategies, our results highlight that it is important to recognize the existence of a potential 
economic benefit of containment measures, particularly when decisively implemented in advanced economies. Although containment may be less effective in emerging markets and low-income countries (e.g., due to large informal sectors), the benefit of reducing uncertainty may still exist in all countries and needs to be taken into account when assessing the trade-off associated with containment measures (as evidenced in China's experience). And in the context of local new COVID waves, the lockdowns can be localized and be combined with other containment measures such as mask wearing.

Second, on macroeconomic projections, ignoring this uncertainty-reducing benefit may lead to static projections. If one only considers the short-term economic disruptions of stringent containment measures while disregarding their medium-term benefit, macroeconomic projections would be overly conservative with containment measures or overly optimistic without them, distorting policy decisions. 


\section{References}

Alvarez, Fernando, David Argente, Francesco Lippi. 2020. “A Simple Planning Problem for COVID-19 Lockdown," Manuscript, University of Chicago.

Arnon, Alexander, John Ricco, and Kent Smetters. 2020. "Epidemiological and Economic Effects of Lockdown," Brookings Papers on Economic Activity Conference Drafts.

Ashraf, Badar Nadeem. 2020. "Economic Impact of Government Actions to Control COVID-19 Pandemic: Evidence from Financial Markets," Journal of Behavioral and Experimental Finance.

Baek, Seungho, Sunil K. Mohanty, and Mina Glambosky. 2020. "COVID-19 and Stock Market Volatility: An Industry Level Analysis," Finance Research Letters, https://doi.org/10.1016/j.frl.2020.101748

Baker, Scott R., Nicholas Bloom, Steven J. Davis, Kyle Kost, Marco Sammon, and Tasaneeya Viratyosin. 2020. “The Unprecedented Stock Market Reaction to COVID-19," Review of Asset Pricing Studies, 0: 1-17, doi/10.1093/rapstu/raaa008/5873533

Barro, Robert J., José F. Ursúa, and Joanna Weng. 2020. “The Coronavirus and the Great Influenza Pandemic: Lessons from the 'Spanish Flu' for the Coronavirus's Potential Effects on Mortality and Economic Activity," NBER Working Paper No. 26866.

Beirne, John, Nuobu Renzhi, Eric Sugandi, and Ulrich Volz. 2020. "Financial Market and Capital Flow Dynamics During the COVID-19 Pandemic," Asian Development Bank Institute Working Paper No. 1158.

Caselli, Francesca, Francesco Grigoli, Weicheng Lian, and Damiano Sandri. 2020. "Protecting Lives and Livelihoods with Early and Tight Lockdowns," IMF Working Paper No. 20/234.

CBOE. 2019. "White Paper: Cboe Volatility Index," https://cdn.cboe.com/resources/futures/vixwhite.pdf.

Chen, Sophia, Deniz Igan, Nicola Pierri, and Andrea F. Presbitero. 2020. "Tracking the Economic Impact of COVID-19 and Mitigation Policies in Europe and the United States," COVID Economics, 36: 124.

Cheng, Ing-Haw. 2020. "Volatility Markets Underreacted to the Early Stages of the COVID-19 Pandemic," Review of Asset Pricing Studies, 10: 635-668.

Chordia, Tarun, Richard Roll, and Avanidhar Subramanyam. 2005. "Evidence on the Speed of Convergence to Market Efficiency," Journal of Financial Economics, 76: 271-292.

Correia, Sergio, Stephan Luck, and Emil Verner. 2020. "Pandemics Depress the Economy, Public Health Interventions Do Not: Evidence from the 1918 Flu," Working Paper.

Deb, Pragyan, Davide Furceri, Jonathan D. Ostry, and Nour Tawk. 2020a. "The Economic Effects of COVID-19 Containment Measures," COVID Economics, 24: 32-75.

Deb, Pragyan, Davide Furceri, Jonathan D. Ostry, and Nour Tawk. 2020b. "The Effect of Containment Measures on the COVID-19 Pandemic," IMF Working Paper No. 20/159.

Eichenbaum, Martin, Sergio Rebelo, and Mathias Trabandt. "The Macroeconomics of Epidemics," March 2020. Northwestern University Working Paper. 
Fernandes, Marcelo, Marcelo C. Medeiros, and Marcel Scharth. 2014. "Modeling and Predicting the CBOE Market Volatility Index." Journal of Banking and Finance, 40: 1-10.

Fotiou, Alexandra, and Andresa Lagerborg. 2021. "Smart Containment: Lessons from Countries with Past Experience," COVID Economics, 74: 94-141.

Goolsbee, Austan, and Chad Syverson. 2020. "Fear, Lockdown, and Diversion: Comparing Drivers of Pandemic Economic Decline,” NBER Working Paper No. 27432.

Gourinchas, Pierre-Olivier. 2020. "Flattening the Pandemic and Recession Curves," https://voxeu.org/ article/flattening-pandemic-and-recession-curves

Hall, Robert E., Charles I. Jones, and Peter J. Klenow. 2020. “Trading Off Consumption and COVID-19 Deaths," Stanford University Working Paper.

Haroon Omair, and Syed Aun R.Rizvi. 2020. "COVID-19: Media Coverage and Financial Markets Behavior-A Sectoral Inquiry," Journal of Behavioral and Experimental Finance, 27, https://doi.org/10.1016/j. jbef.2020.100343

Jackwerth, Jens. 2020. “What Do Index Options Teach Us About COVID-19?” Review of Asset Pricing Studies, 10: 618-634.

Jones, Callum, Thomas Philippon, and Venky Venkateswaran. 2020. "Optimal Mitigation Policies in A Pandemic," NYU Working Paper.

Kok, Jason Lih Cheng. 2020. "Short-term Trade-off between Stringency and Economic Growth," Covid Economics, 60: 172-189.

Marshall, Ben R., Nhut H. Nguyen, and Nuttawat Visaltanachoti. 2017. "A Note on Intraday Event Studies," Working Paper.

McWilliams, Abagail., and Siegel, Donald. 1997. "Event Studies in Management Research: Theoretical and Empirical Issues," The Academy of Management Journal, 40(3): 626-657.

Miles, David K., Michael Stedman, and Adrian H. Heald. 2020. "Stay at Home, Protect the National Health Service, Save Lives: A Cost Benefit Analysis of the Lockdown in the United Kingdom," International Journal of Clinical Practice.

Sheridan, Adam, Asger Lau Andersen, Emil Toft Hansen, and Niels Johannesen. 2020. "Social Distancing Laws Cause Only Small Losses of Economic Activity During The COVID-19 Pandemic in Scandinavia," PNAS August 25, 2020117 (34), https://doi.org/10.1073/pnas.2010068117

Smith, Simon. February 27, 2013. "FTSE introduces UK and Italian equivalents of the VIX,"ETF Strategy, https://www.etfstrategy.com/ftse-introduces-uk-and-italian-equivalents-of-the-vix-the-ftseimplied-volatility-index-series-ivi-11335/

Zaremba, Adam, Renatas Kizys, David Y. Aharond, and Ender Demir. 2020. "Infected Markets: Novel Coronavirus, Government Interventions, and Stock Return Volatility around the Globe," Finance Research Letters, 35, https://doi.org/10.1016/j.frl.2020.101597

Zhang, Dayong, Min Hu, and Qiang Ji. 2020. "Financial Markets under the Global Pandemic of COVID19," Finance Research Letters, 35, https://doi.org/10.1016/j.frl.2020.101528 


\section{Appendices}

\section{Appendix 1. Estimating the Event Time: An Example}

This appendix provides an example for estimating the event minute when this information is not readily available. The times for different events are estimated differently, and the following threestep procedure is used to estimate the time for France's reopening announcement.

Step 1: Identifying the publication time of the relevant news article. After an extensive search, we found that a French newspaper, France24, published an article on this event at 14:38 of July 5, 2020. See this link.

Step 2: Confirming the time zone of the publication time. We then checked another article by France 24 published on the day when we were doing the search (November 12, 2020). It had already published an article about the US election at "11:33", when the actual time in Washington DC was only 8:39 am (Eastern time). This means that the time shown in France24's article is in French time.

Step 3: Inferring the time of the announcement. The article about France's easing (i.e., the article in Step 1) is long and may take some time to prepare, so it is hard to estimate the time of the announcement. However, the same article cited a reporter's tweet, which shows 10:15 am of May 7, 2020 (and it must be in French time, according to Step 1). Since sending a tweet takes only a few minutes, we can infer that the announcement time must be a few minutes before 10:15 am French time. In the end, we use 10 am French time of May 7 as our event time for this event, which is 4 am Eastern time (as shown in Figure 3). 


\section{Appendix Figure 1. Prediction Errors for Six-Month Volatility (Easing)}

1.5

0.5

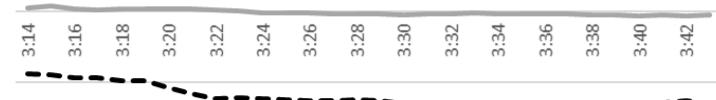

Germany Easing (Apr 15) (Euro Market)

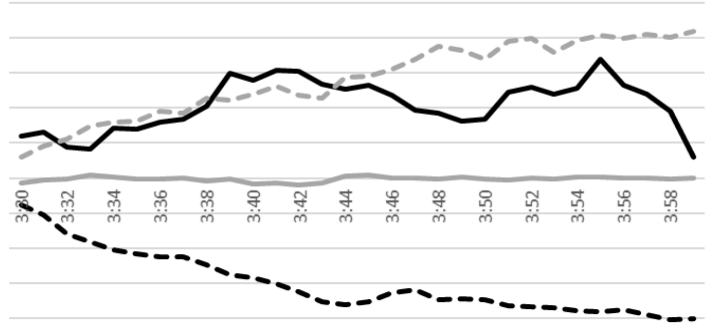

Germany Easing (Apr 15) (Local Market)
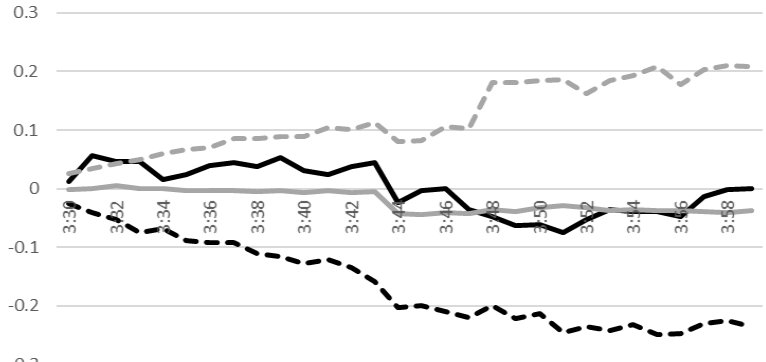

$-0.3$

France Easing (May 7) (Euro Market)

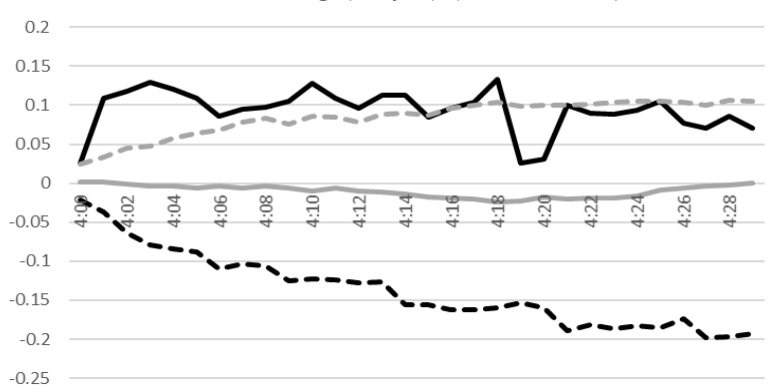

\section{Appendix Figure 2. Prediction Errors for Six-Month Volatility (Retightening)}

Italy Retightening (Oct 25) (Euro Market)

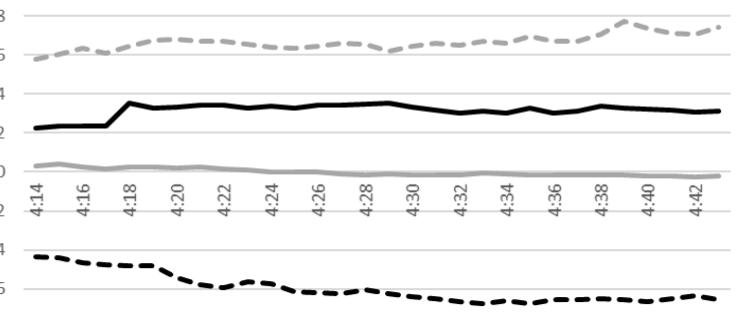

Germany Retightening (Oct 28) (Euro Market)
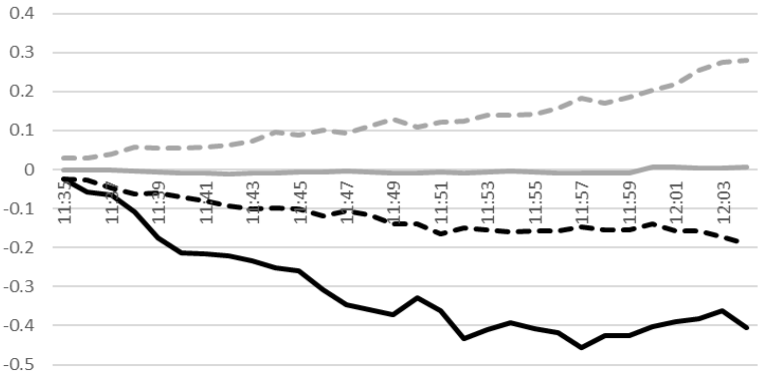

Germany Retightening (Oct 28) (Local Market)

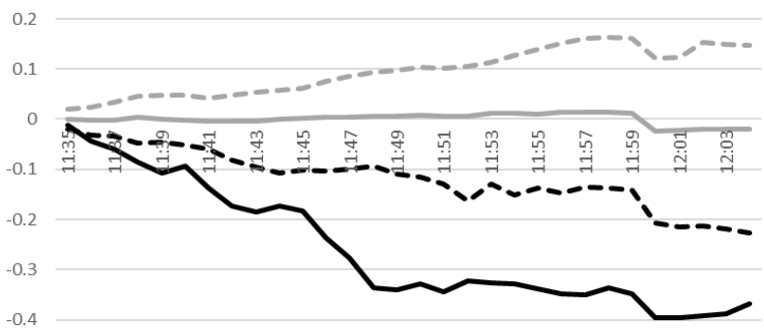

France Retightening (Oct 28) (Euro Market)

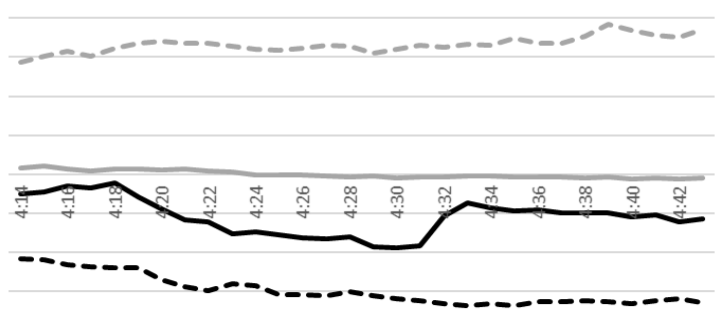




\section{Appendix Figure 3. Volatility Responses Across Maturities: Italy's Initial Tightening}
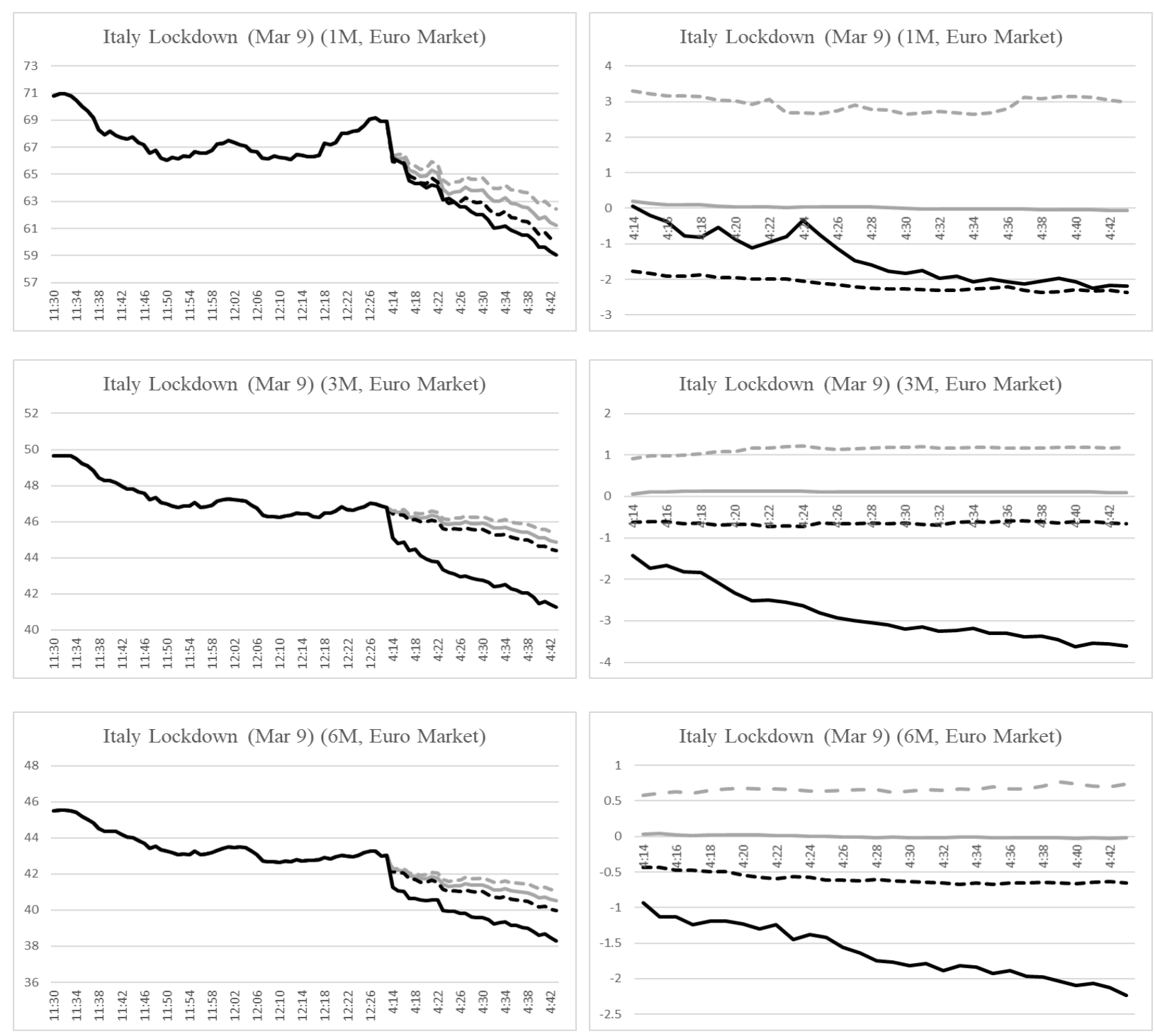

counterfactual - _ - 90\% lower end - - $-90 \%$ higher end —actual 


\section{Appendix Figure 4. ARIMA Model: Six-Month Volatility Indices (Initial Tightening)}
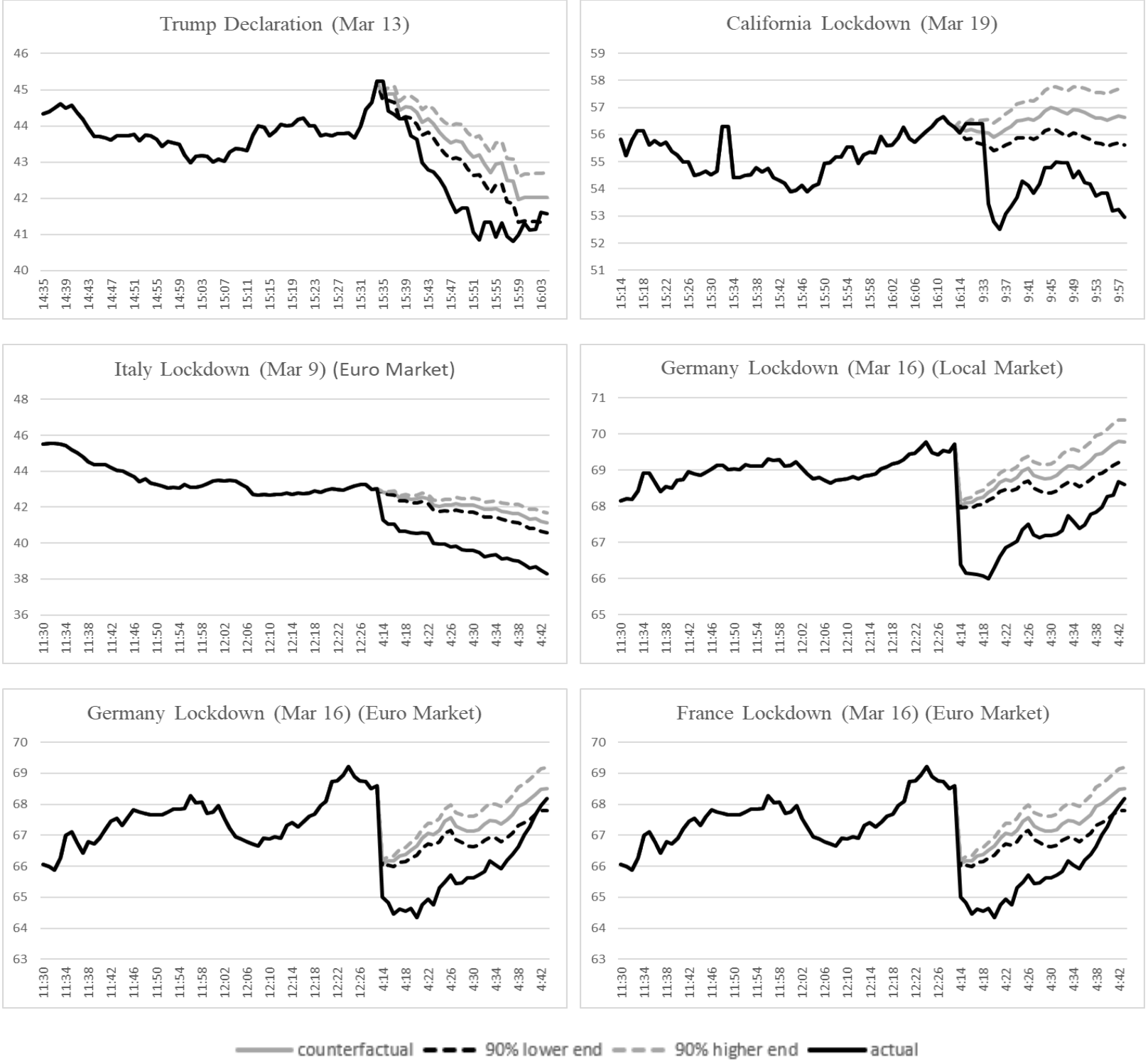


\section{Appendix Figure 5. ARIMA Model: Six-Month Volatility Indices (Easing)}

Italy Easing (Apr 20) (Euro Market)

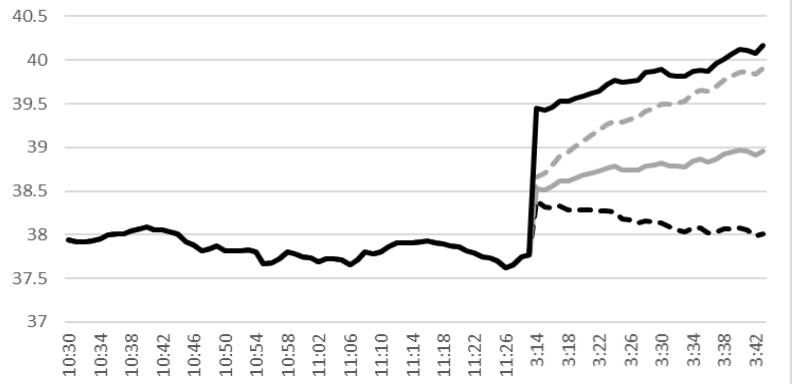

Germany Easing (Apr 15) (Euro Market)

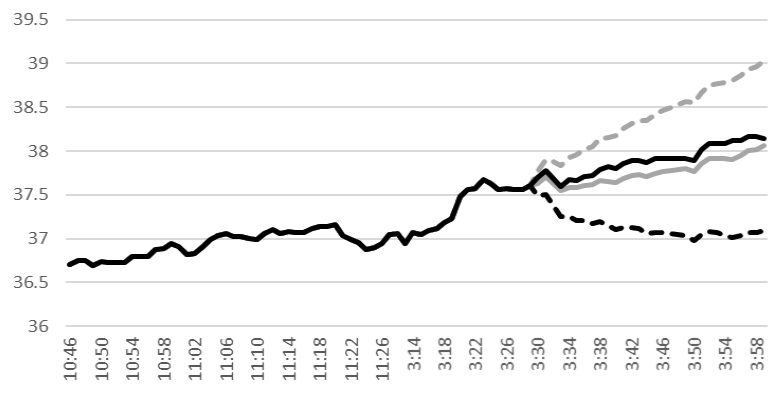

Germany Easing (Apr 15) (Local Market)
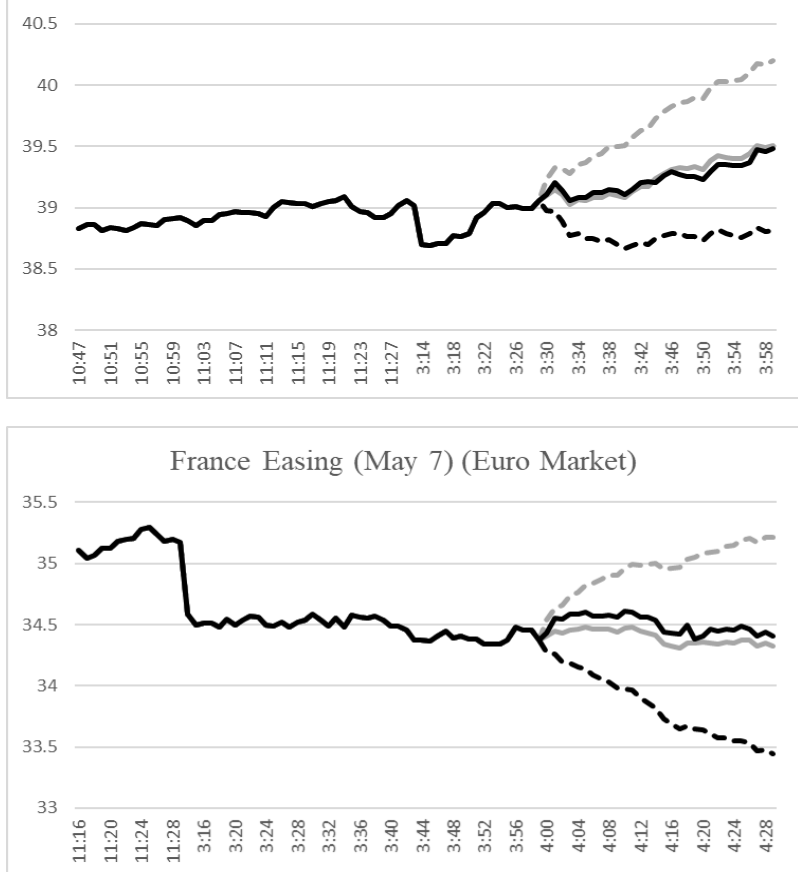

Appendix Figure 6. ARIMA Model: Six-Month Volatility Indices (Retightening)

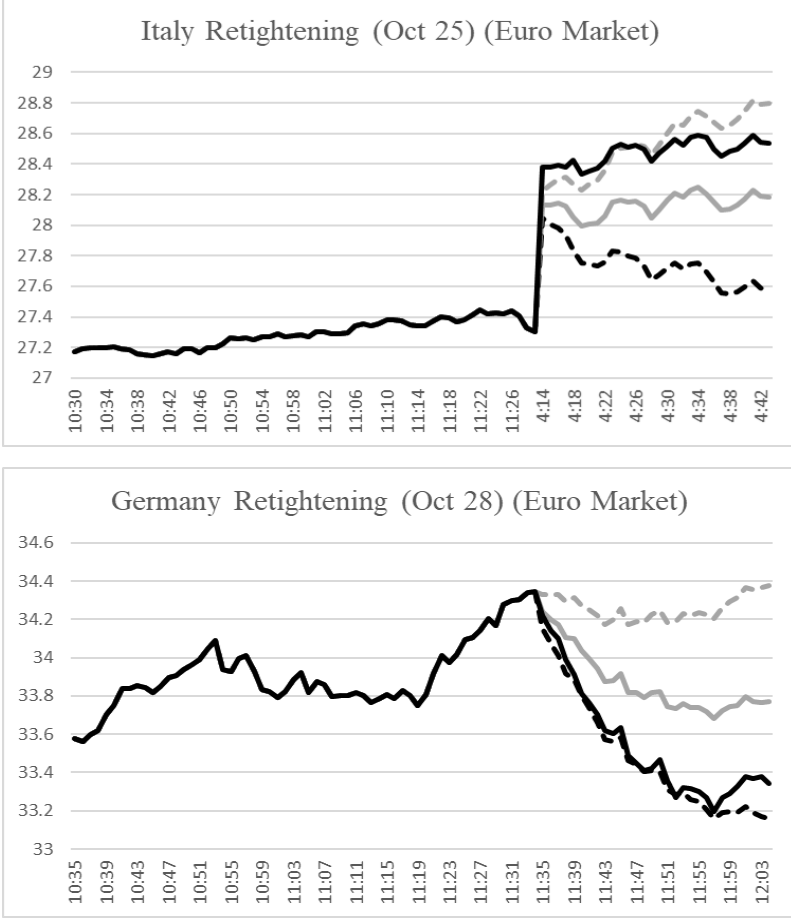

Germany Retightening (Oct 28) (Local Market)

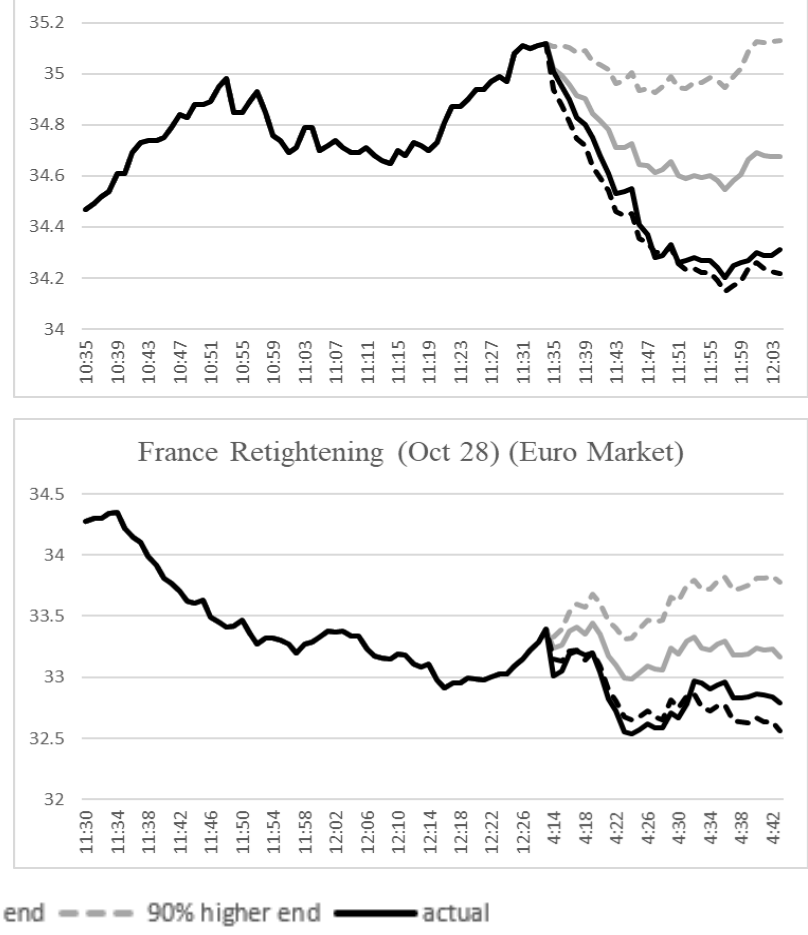




\section{Appendix Figure 7. EGARCH Model: Six-Month Volatility Indices (Initial Tightening)}

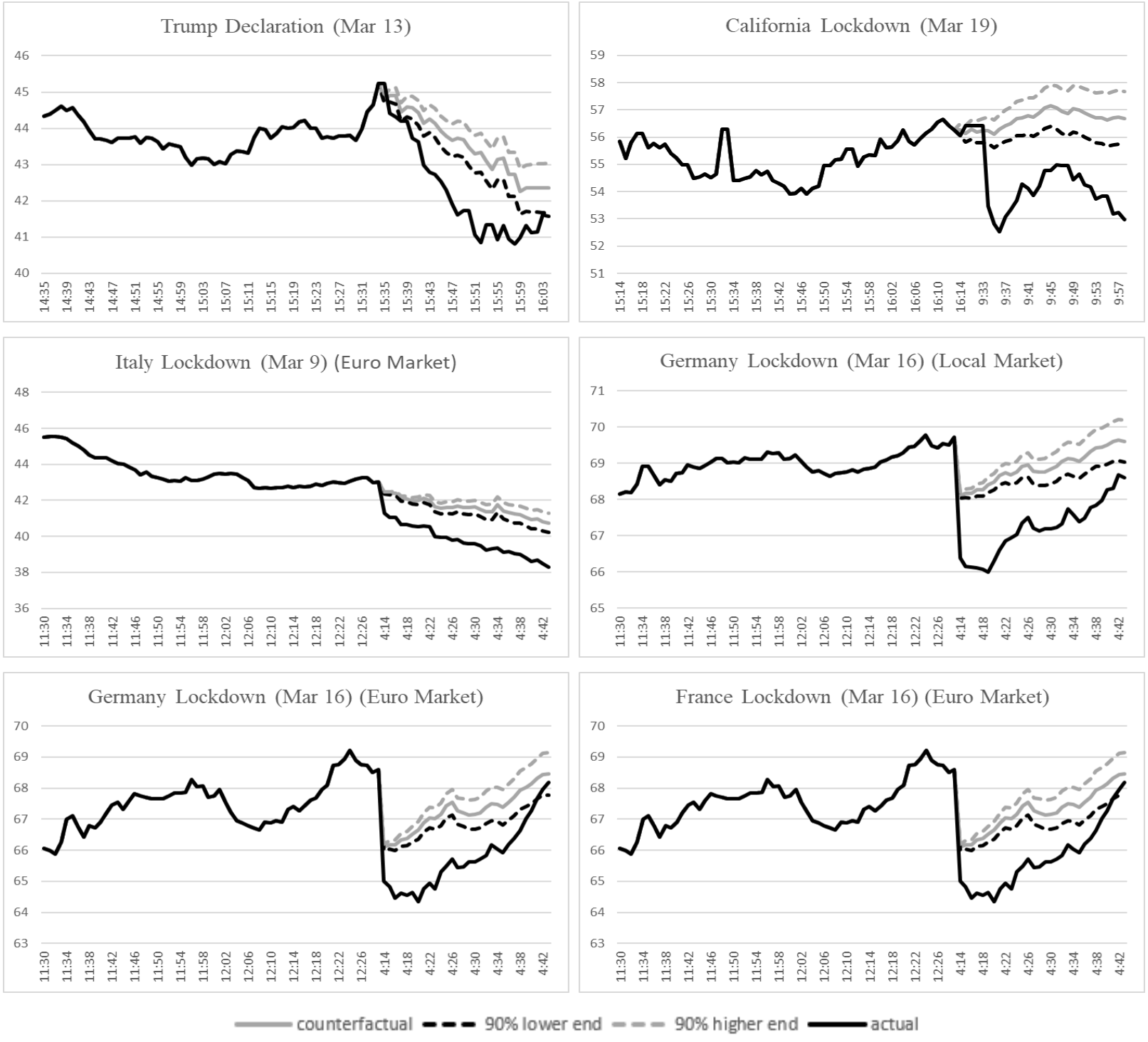




\section{Appendix Figure 8. EGARCH Model: Six-Month Volatility Indices (Easing)}

Italy Easing (Apr 20) (Euro Market)

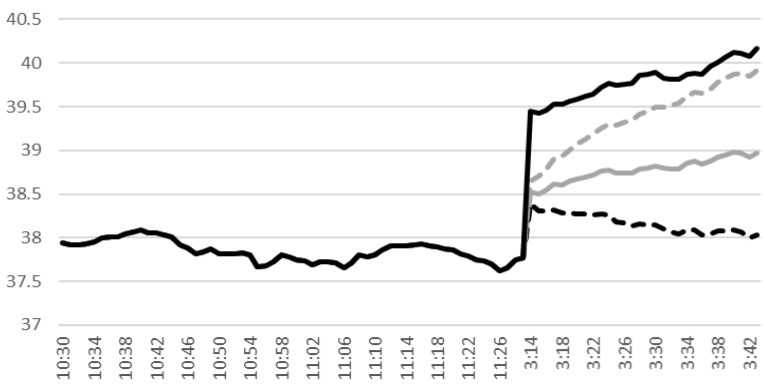

Germany Easing (Apr 15) (Euro Market)

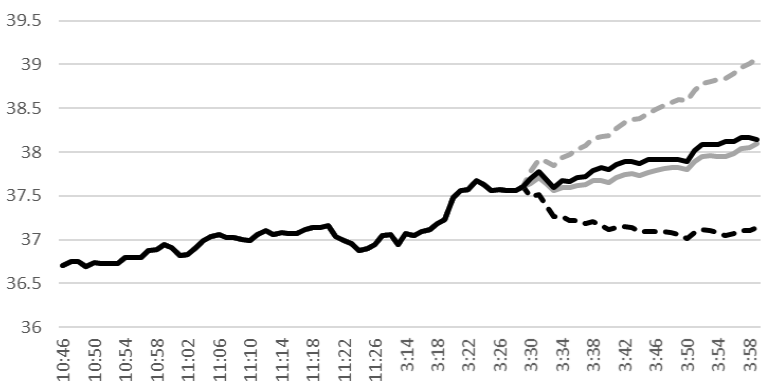

Germany Easing (Apr 15) (Local Market)

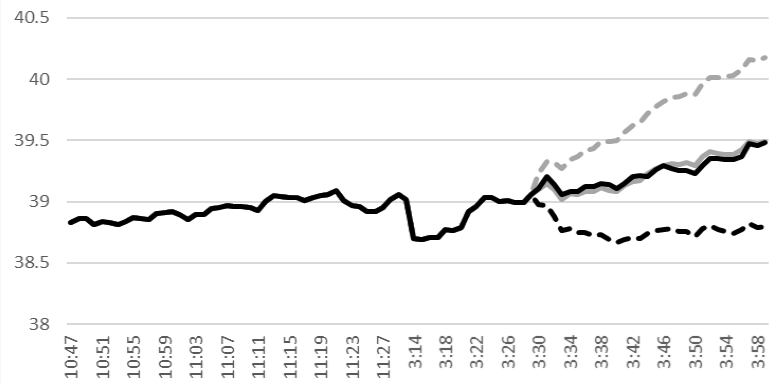

France Easing (May 7) (Euro Market)

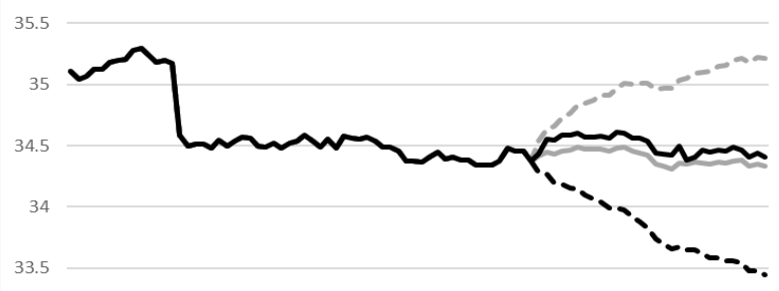

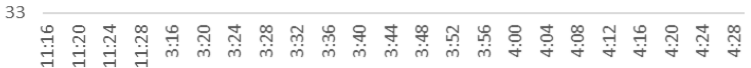

\section{Appendix Figure 9. EGARCH Model: Six-Month Volatility Indices (Retightening)}
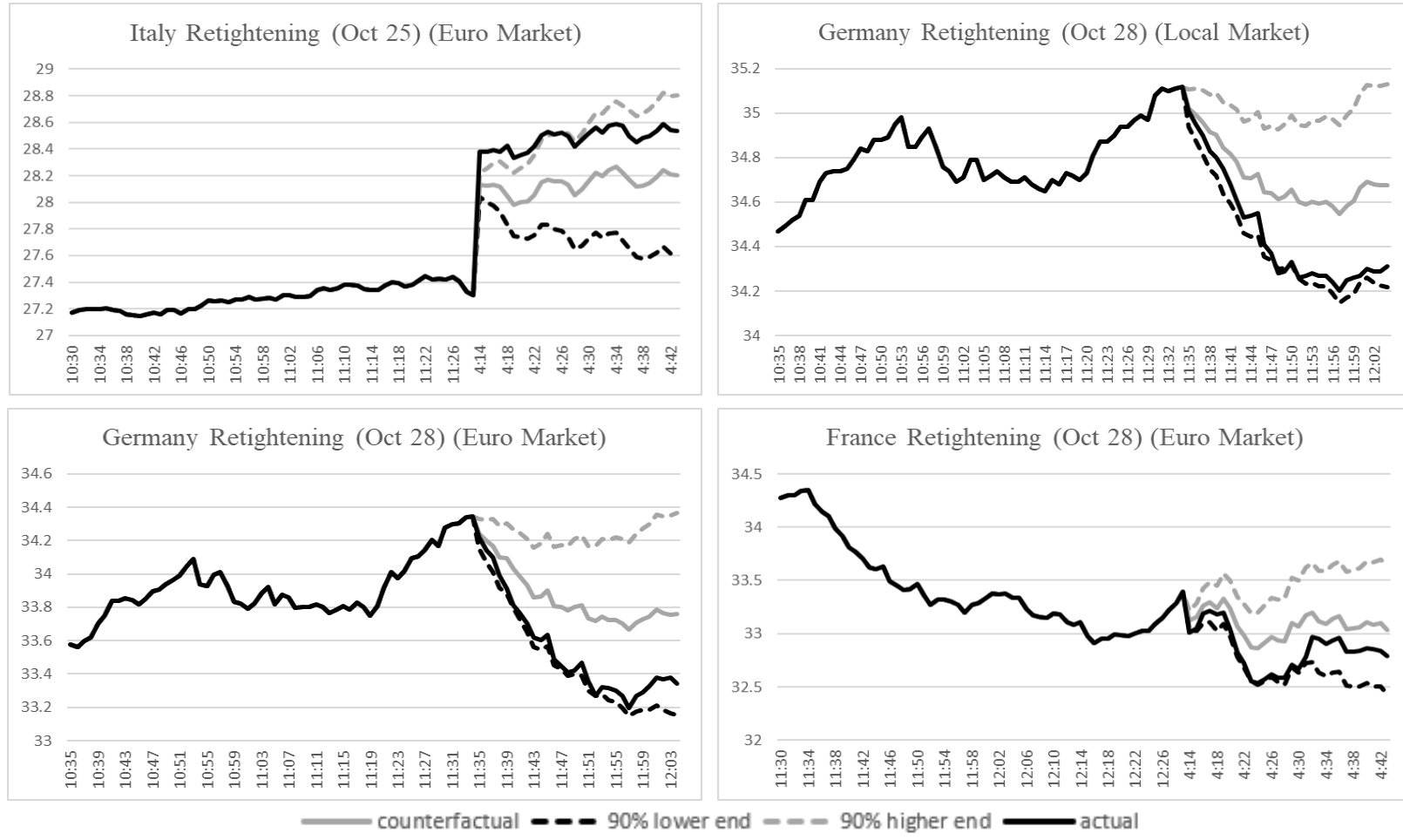
Appendix Table 1. Summary Statistics of Panel Regression Data

\begin{tabular}{|c|c|c|c|c|c|}
\hline & Number of obs & Mean & $\mathrm{Sd}$ & Min & Max \\
\hline \multicolumn{6}{|c|}{ Panel (A): Initial tightening } \\
\hline V_3M_pct & 401 & 108.3 & 922.4 & $-4,881.7$ & $4,013.7$ \\
\hline V_6M_pct & 401 & 96.5 & 791.8 & $-4,875.3$ & $3,436.8$ \\
\hline StringencyIndex & 401 & 41.8 & 35.5 & 0.0 & 93.5 \\
\hline Cases_pct & 401 & 18.2 & 37.4 & 0.0 & 400.0 \\
\hline Cases_pct_SI & 401 & 660.3 & $1,263.5$ & 0.0 & $11,174.8$ \\
\hline StockPrice_pct & 401 & -23.4 & 296.3 & $-1,692.4$ & $1,097.6$ \\
\hline StockPrice_std & 401 & 45.6 & 72.9 & 0.3 & 804.3 \\
\hline \multicolumn{6}{|c|}{ Panel (B): Easing tightening } \\
\hline V_3M_pct & 257 & -11.3 & 625.0 & $-2,487.0$ & $3,672.6$ \\
\hline V_6M_pct & 257 & -16.0 & 450.1 & $-1,252.8$ & $2,705.7$ \\
\hline StringencyIndex & 257 & 64.6 & 9.6 & 42.6 & 93.5 \\
\hline Cases_pct & 257 & 1.0 & 1.1 & 0.1 & 7.5 \\
\hline Cases_pct_SI & 257 & 66.9 & 81.9 & 3.4 & 519.1 \\
\hline StockPrice_pct & 257 & 21.8 & 169.5 & -589.4 & 567.3 \\
\hline StockPrice_std & 257 & 30.5 & 34.4 & 0.4 & 153.4 \\
\hline \multicolumn{6}{|c|}{ Panel (C): Retightening stage } \\
\hline V_3M_pct & 289 & -1.9 & 442.3 & $-2,195.0$ & $2,440.0$ \\
\hline V_6M_pct & 289 & -5.2 & 270.1 & -730.6 & $1,553.5$ \\
\hline StringencyIndex & 289 & 57.8 & 8.6 & 43.5 & 69.9 \\
\hline Cases_pct & 289 & 1.4 & 1.4 & 0.0 & 9.3 \\
\hline Cases_pct_SI & 289 & 77.5 & 81.6 & 1.5 & 628.6 \\
\hline StockPrice_pct & 289 & 1.2 & 114.4 & -437.5 & 322.1 \\
\hline StockPrice_std & 289 & 25.4 & 28.3 & 0.3 & 175.6 \\
\hline
\end{tabular}

Notes: $(1)$ pct $=$ percent change; std = standard deviation; Cases_pct_SI is the interaction of COVID case percent change and stringency index. (2) Because of the rescaling, the units of the volatility percent change (e.g., V_3M_pct) and of the stock price percent change are basis point (i.e., 1/100 percent); the units of the Cases_pct and StringencyIndex remain as percent. 
Appendix Table 2. Initial Tightening Stage Panel Regressions in the Benchmark Model

\begin{tabular}{lcccccc}
\hline & $(1)$ & $(2)$ & $(3)$ & $(4)$ & $(5)$ & $(6)$ \\
& SI & Cases & Interaction & SI & Cases & Interaction \\
& FE & FE & FE & RE & RE & RE \\
\hline StringencyIndex & -1.868 & & -1.462 & $-1.996^{*}$ & & -1.515 \\
& $(0.101)$ & & $(0.237)$ & $(0.072)$ & & $(0.213)$ \\
Cases_pct & & $3.092^{* * *}$ & $3.358^{* *}$ & & $3.173^{* * *}$ & $3.418^{* * *}$ \\
& & $(0.004)$ & $(0.012)$ & & $(0.002)$ & $(0.010)$ \\
Cases_pct_SI & & & -0.018 & & & -0.019 \\
& & & $(0.659)$ & & & $(0.640)$ \\
Observations & 401 & 401 & 401 & 401 & 401 & 401 \\
R-squared & 0.007 & 0.021 & 0.027 & & & \\
\hline
\end{tabular}

Notes: (1) p-values are in parentheses. (2) FE = fixed effect; $\mathrm{RE}=$ random effect. (3) Constant not shown.

Appendix Table 3. Initial Tightening Stage Panel Regressions in the Stock Price Model

\begin{tabular}{lcccccc}
\hline & $(1)$ & $(2)$ & $(3)$ & $(4)$ & $(5)$ & $(6)$ \\
& SI & Cases & Interaction & SI & Cases & Interaction \\
& FE & FE & FE & RE & RE & RE \\
\hline StringencyIndex & -0.850 & & 0.425 & -0.998 & & 0.354 \\
& $(0.321)$ & & $(0.650)$ & $(0.233)$ & & $(0.701)$ \\
Cases_pct & & 0.312 & $2.082^{* *}$ & & 0.436 & $2.196^{* *}$ \\
& & $(0.706)$ & $(0.037)$ & & $(0.595)$ & $(0.025)$ \\
Cases_pct_SI & & & $-0.099 * * *$ & & & $-0.101 * * *$ \\
& & & $(0.002)$ & & & $(0.001)$ \\
StockPrice_pct & $-1.778^{* * *}$ & $-1.777 * * *$ & $-1.830 * * *$ & $-1.774 * * *$ & $-1.771 * * *$ & $-1.825 * * *$ \\
& $(0.000)$ & $(0.000)$ & $(0.000)$ & $(0.000)$ & $(0.000)$ & $(0.000)$ \\
Lag_StockPrice_pct & $0.174 *$ & $0.173 *$ & 0.131 & $0.178 *$ & $0.178 *$ & 0.135 \\
Observations & $(0.086)$ & $(0.094)$ & $(0.206)$ & $(0.077)$ & $(0.082)$ & $(0.188)$ \\
R-squared & 396 & 396 & 396 & 396 & 396 & 396
\end{tabular}

Notes: (1) p-values are in parentheses. (2) $\mathrm{FE}=$ fixed effect; $\mathrm{RE}=$ random effect. (3) Constant not shown. 
Appendix Table 4. Seemingly Unrelated Regression Results (Full Sample, All Stages)

\begin{tabular}{|c|c|c|c|c|}
\hline & $\begin{array}{c}(1) \\
\text { V_3M_pct }\end{array}$ & $\begin{array}{c}(2) \\
\text { V_3M_pct }\end{array}$ & $\begin{array}{c}(3) \\
\text { V_3M_pct }\end{array}$ & $\begin{array}{c}(4) \\
\text { V_3M_pct }\end{array}$ \\
\hline \multicolumn{5}{|l|}{ V_3M_pct } \\
\hline StringencyIndex & $\begin{array}{c}-3.287 * * * \\
(0.000)\end{array}$ & & $\begin{array}{c}-2.825 * * * \\
(0.004)\end{array}$ & $\begin{array}{l}-1.004 \\
(0.183)\end{array}$ \\
\hline Cases_pct & & $\begin{array}{c}4.448 * * * \\
(0.000)\end{array}$ & $\begin{array}{c}3.452 * * * \\
(0.004)\end{array}$ & $\begin{array}{c}1.942 * * \\
(0.030)\end{array}$ \\
\hline Cases_pct_SI & & & $\begin{array}{c}0.025 \\
(0.468)\end{array}$ & $\begin{array}{c}-0.080 * * * \\
(0.003)\end{array}$ \\
\hline StockPrice_pct & & & & $\begin{array}{c}-2.234 * * * \\
(0.000)\end{array}$ \\
\hline Lag_StockPrice_pct & & & & $\begin{array}{l}-0.027 \\
(0.743)\end{array}$ \\
\hline (mean) Std_SP & & & & $\begin{array}{c}-0.837 * \\
(0.069)\end{array}$ \\
\hline Lag_StockPrice_std & & & & $\begin{array}{c}1.678 * * * \\
(0.000)\end{array}$ \\
\hline V_6M_pct & & & & \\
\hline StringencyIndex & $\begin{array}{c}-2.423 * * * \\
(0.001)\end{array}$ & & $\begin{array}{c}-1.756^{* *} \\
(0.027)\end{array}$ & $\begin{array}{l}-0.485 \\
(0.400)\end{array}$ \\
\hline Cases_pct & & $\begin{array}{c}3.500 * * * \\
(0.000)\end{array}$ & $\begin{array}{c}3.457 * * * \\
(0.000)\end{array}$ & $\begin{array}{c}2.124 * * * \\
(0.002)\end{array}$ \\
\hline Cases_pct_SI & & & $\begin{array}{l}-0.012 \\
(0.660)\end{array}$ & $\begin{array}{c}-0.097 * * * \\
(0.000)\end{array}$ \\
\hline StockPrice_pct & & & & $\begin{array}{c}-1.902 * * * \\
(0.000)\end{array}$ \\
\hline Lag_StockPrice_pct & & & & $\begin{array}{c}0.101 \\
(0.109)\end{array}$ \\
\hline (mean) Std_SP & & & & $\begin{array}{c}-2.060 * * * \\
(0.000)\end{array}$ \\
\hline Lag_StockPrice_std & & & & $\begin{array}{c}2.937 * * * \\
(0.000)\end{array}$ \\
\hline Observations & 924 & 924 & 924 & 919 \\
\hline$R^{2}$ & 0.014 & 0.026 & 0.034 & 0.469 \\
\hline
\end{tabular}

Notes: (1) p-values are in parentheses. (2) FE = fixed effect; $\mathrm{RE}=$ random effect. (3) Constant not shown. 